\title{
Methods and Tools for Overcoming the Barriers to Servitization and Service Excellence
}

\subsection{How to Build Your Service Excellence Roadmap}

This section is intended to help you define where you need to get to and how you are going to get there. For every firm the starting point is different, and the end point will be different, so the route has to be different: this is because context matters (Dmitrijeva et al., 2020).

The development of services in an industrial context is always an evolution: we all have different starting points and different destinations. Your roadmap has to fit within your firm's vision and its longer-term strategy but also remain actionable. And that is not an easy balance to achieve.

What is important is that you first sketch out your service excellence roadmap, so you know what you are planning, when, and why. Find your preferred partners to work together with - this can be inside your own firm, as well as suppliers and customers.

To do this effectively, we think it is best to agree a service vision, and once you have this, you can then brainstorm the issues that are preventing you from delivering services (use Post-its). These can then be segmented by the different categories and individual barriers. From there, you can start to prioritize them in a two-by-two grid. Then, and only then, you can start to build up a roadmap based on your priorities and the challenges you face. Start with the easy/high-impact improvements, and then move down the list; be careful as some may be dependent on others. Review every 9-12 months and adjust, because the more you change, the more you will learn, and you will then want to fine-tune your approach.

If you pass on the tasks to others, hold a short regular call with your team to ensure progress is being made. If not, listen to understand where the barriers are and how you could help them overcome what is causing the problem.

With your roadmap, make sure you find people outside of your business and your firm who you can talk with and discuss your plans. It's a tough business change to make, and you will need the support of others to find ways to break though barriers (Fig. 3.1). 


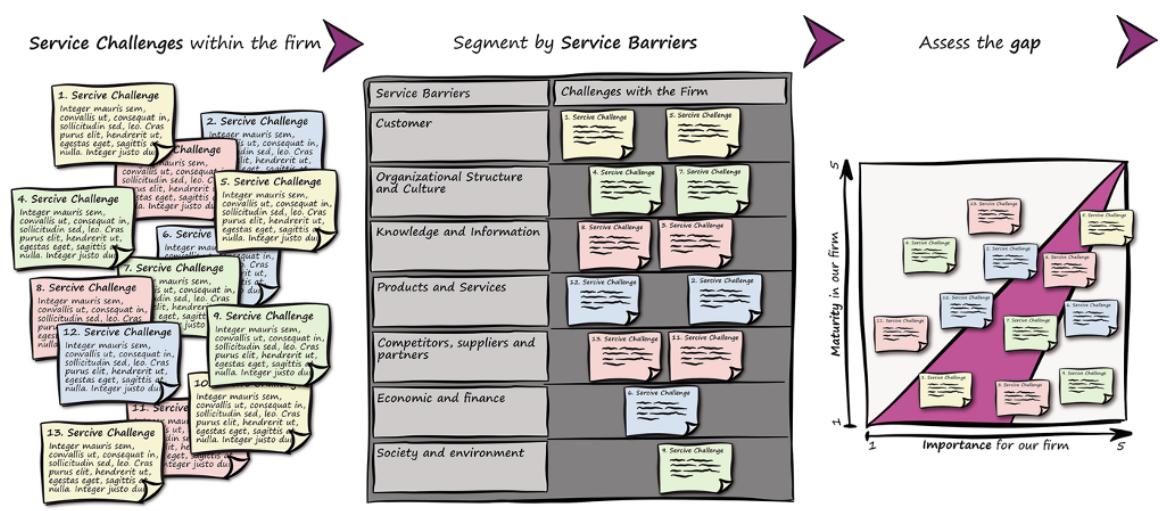

Prioritise the Service Challenges
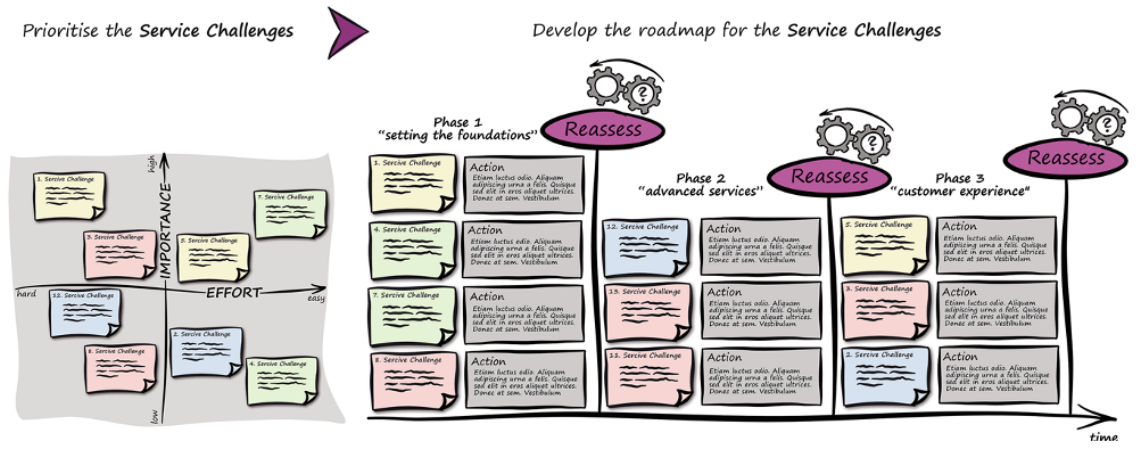

Fig. 3.1 A process to help build your service excellence roadmap (illustration by Annick Holland, authors' work)

\subsection{Service Methods and Tools}

This section contains a brief description of methods and tools that we have found are useful in creating or delivering services, both from our direct experience and from the feedback on our interviews with businesses. Specifically, Table 3.1 lists some general business tools as well as specific tools that are associated with the productservice system (PSS) implementation. The tools that we also found useful as general management tools are marked *.

\section{Avatar Map}

The avatar map is core to understanding the equipment or products that you sell to your customers. It is in effect the "persona for the machine." It's a tool that engineers find easy to complete as they can understand the inputs, possible data flows, wastes, and value.

Several avatars can be used to represent a flow within the customer's plant, allowing you to quickly figure out the relationships between the machines. The 
Table 3.1 Cases and tools (compiled by authors)

\begin{tabular}{|c|c|c|c|c|c|c|c|c|c|c|c|c|c|c|c|c|c|c|c|c|c|c|}
\hline & 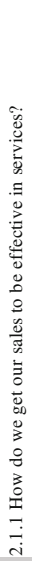 & 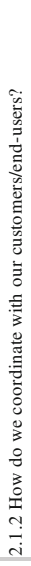 & 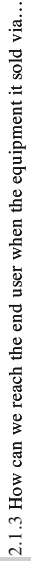 & 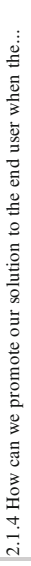 & 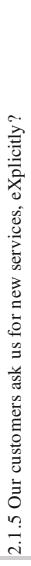 & 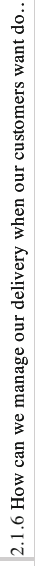 & 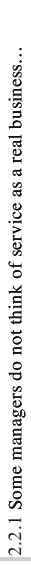 & 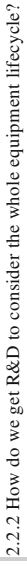 & 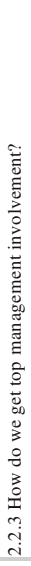 & 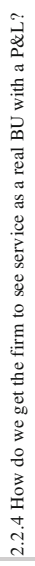 & 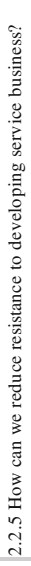 & 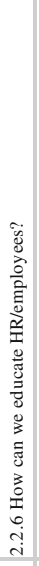 & 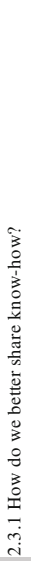 & 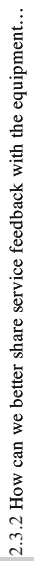 & 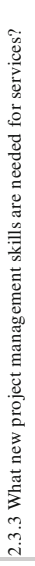 & 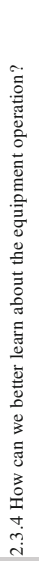 & 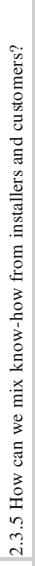 & 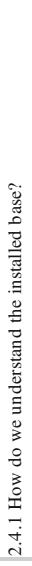 & 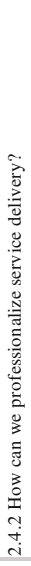 & 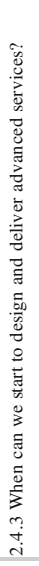 & 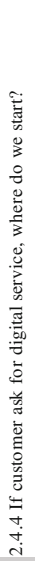 & 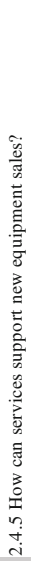 \\
\hline Avatar map & & & & & & $\mathrm{x}$ & $\mathrm{x}$ & $\mathrm{x}$ & & & $\mathrm{x}$ & $\mathrm{x}$ & $\mathrm{x}$ & $x$ & & $\mathrm{x}$ & $\mathrm{x}$ & $x$ & $\mathrm{x}$ & $\mathrm{x}$ & $x$ & \\
\hline Business model canvas & & & & & $\mathrm{x}$ & & $x$ & & $x$ & $x$ & & & $x$ & & & & & & & & & \\
\hline Business Process mapping & & & & & & & & & $\mathrm{x}$ & $\mathrm{x}$ & & & $\mathrm{x}$ & & & $\mathrm{x}$ & & $\mathrm{x}$ & & & $\mathrm{x}$ & \\
\hline Case/actor matrix & & $\mathrm{x}$ & $\mathrm{x}$ & $\mathrm{x}$ & & $\mathrm{x}$ & & $\mathrm{x}$ & & & & & $\mathrm{x}$ & & $\mathrm{x}$ & $x$ & & $\mathrm{x}$ & $\mathrm{x}$ & $\mathrm{x}$ & $\mathrm{x}$ & $\mathrm{x}$ \\
\hline \multicolumn{23}{|l|}{ Context map } \\
\hline Cradle-to-grave lifecycle map & & & & & $\mathrm{x}$ & $\mathrm{x}$ & $x$ & $\mathrm{x}$ & & & $x$ & $x$ & & $x$ & & $x$ & $x$ & $x$ & $x$ & $\mathrm{x}$ & $x$ & $x$ \\
\hline Cradle-to-grave lifecycle visual mapping & & & $x$ & $x$ & $\mathrm{x}$ & $x$ & $x$ & $x$ & & & $x$ & $x$ & $x$ & & & $x$ & $x$ & $x$ & $x$ & $x$ & $x$ & $x$ \\
\hline Customer jobs-to-be-done & $x$ & $\mathrm{x}$ & $x$ & $x$ & $\mathrm{x}$ & & & $\mathrm{x}$ & & & & & & & & $x$ & $x$ & $x$ & $\mathrm{x}$ & $x$ & $x$ & $x$ \\
\hline Customer value proposition & $\mathrm{x}$ & $\mathrm{x}$ & $x$ & $x$ & $x$ & $\mathrm{x}$ & & & $x$ & $x$ & & & & & $x$ & $x$ & & & $x$ & $x$ & $x$ & $x$ \\
\hline \multicolumn{23}{|l|}{ Decision matrix } \\
\hline Ecosystem mapping & & $x$ & & & & & & & & & & & $x$ & $x$ & $x$ & & & & & & & $x$ \\
\hline Detailed empathy card & $x$ & & $x$ & $x$ & $x$ & & & & & & & & $x$ & $x$ & $x$ & $x$ & & & & & & $x$ \\
\hline Empathy maps & & $x$ & $x$ & $x$ & & & & & & & $x$ & & & $x$ & & & & & $x$ & $x$ & & $x$ \\
\hline \multicolumn{23}{|l|}{ Feedback grid } \\
\hline \multicolumn{23}{|l|}{ Feedback sheet } \\
\hline \multicolumn{23}{|l|}{ Five whys } \\
\hline Job-to-be-done insights & $x$ & & & & $x$ & $x$ & $x$ & $\mathrm{x}$ & & & & & & & & $x$ & & $x$ & $x$ & & $x$ & $x$ \\
\hline Job-to-be-done outcomes & $x$ & & & & $x$ & & $x$ & $x$ & & & & & & & & $x$ & & $x$ & $x$ & & $x$ & $x$ \\
\hline Keeping focused & $x$ & & & & $x$ & $x$ & & & & & & & & & & & & & & & & \\
\hline Metric cascades & & & & & & & & & $\mathrm{x}$ & $\mathrm{x}$ & & & & & $x$ & $\mathrm{x}$ & $\mathrm{x}$ & $x$ & $\mathrm{x}$ & $x$ & $x$ & $\mathrm{x}$ \\
\hline Personas & $x$ & $\mathrm{x}$ & $x$ & $\mathrm{x}$ & $\mathrm{x}$ & $x$ & & & & & $x$ & & & & $x$ & $x$ & $x$ & & & $x$ & $\mathrm{x}$ & $x$ \\
\hline \multicolumn{23}{|l|}{ Pitching planning } \\
\hline \multicolumn{23}{|l|}{ Problem breakdown with the five Ws } \\
\hline Service blueprint & $x$ & $x$ & & $x$ & $\mathrm{x}$ & $x$ & $x$ & $\mathrm{x}$ & $x$ & $x$ & $x$ & $x$ & $x$ & $\mathrm{x}$ & $\mathrm{x}$ & $x$ & $x$ & $\mathrm{x}$ & $\mathrm{x}$ & $x$ & $\mathrm{x}$ & $x$ \\
\hline \multicolumn{23}{|l|}{ Storyboarding } \\
\hline Understanding your business & & & & & & & & & $x$ & $x$ & $x$ & $x$ & $x$ & & & $x$ & & & & $x$ & & \\
\hline Visual journey map - high level & $\mathrm{x}$ & $\mathrm{x}$ & $\mathrm{x}$ & $\mathrm{x}$ & & & $\mathrm{x}$ & & $x$ & $x$ & & $x$ & $x$ & $\mathrm{x}$ & & $x$ & & & $\mathrm{x}$ & $x$ & $\mathrm{x}$ & \\
\hline Visual journey map - detail level & $x$ & $x$ & $\mathrm{x}$ & $\mathrm{x}$ & & & $x$ & & $\mathrm{x}$ & $x$ & $x$ & $x$ & $x$ & $x$ & & $x$ & & & $x$ & $x$ & $x$ & \\
\hline
\end{tabular}


Table 3.1 (continued)

\begin{tabular}{|c|c|c|c|c|c|c|c|c|c|c|c|c|c|c|c|c|c|}
\hline & 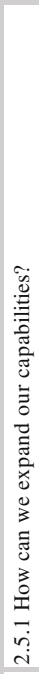 & 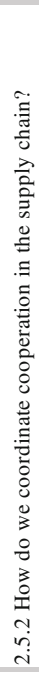 & 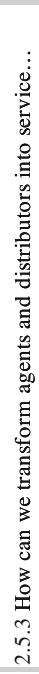 & 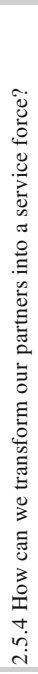 & 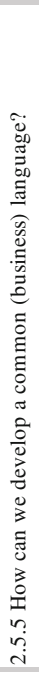 & 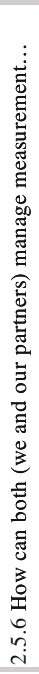 & 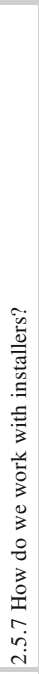 & 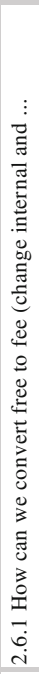 & 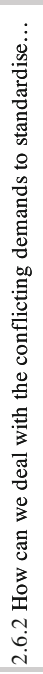 & 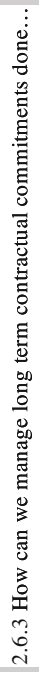 & 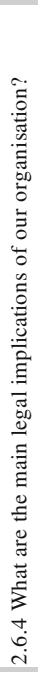 & 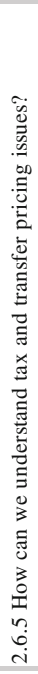 & 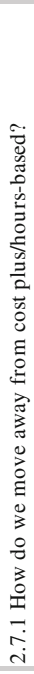 & 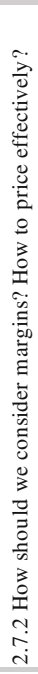 & 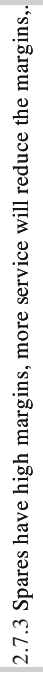 & 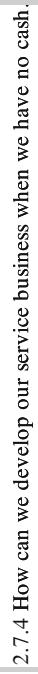 & 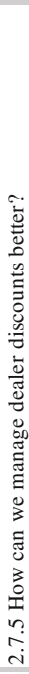 \\
\hline Avatar map & $\mathrm{x}$ & $\mathrm{x}$ & & & $\mathrm{x}$ & $\mathrm{x}$ & $\mathrm{x}$ & & & & & & & $\mathrm{x}$ & $\mathrm{x}$ & $\mathrm{x}$ & \\
\hline Business model canvas & & & $\mathrm{x}$ & $\mathrm{x}$ & $\mathrm{x}$ & & & $\mathrm{x}$ & $\mathrm{x}$ & $\mathrm{x}$ & $\mathrm{x}$ & $\mathrm{x}$ & $\mathrm{x}$ & $\mathrm{x}$ & $\mathrm{x}$ & $\mathrm{x}$ & $\mathrm{x}$ \\
\hline Business Process mapping & & $\mathrm{x}$ & $\mathrm{x}$ & $x$ & & & & $\mathrm{x}$ & $\mathrm{x}$ & $\mathrm{x}$ & $\mathrm{x}$ & $x$ & $\mathrm{x}$ & & & $x$ & $\mathrm{x}$ \\
\hline Case/actor matrix & $\mathrm{x}$ & $\mathrm{x}$ & $x$ & $\mathrm{x}$ & & & $\mathrm{x}$ & & $\mathrm{x}$ & $\mathrm{x}$ & $\mathrm{x}$ & $\mathrm{x}$ & & & & $\mathrm{x}$ & \\
\hline \multicolumn{18}{|l|}{ Context map } \\
\hline Cradle-to-grave lifecycle map & $\mathrm{x}$ & $\mathrm{x}$ & & & $\mathrm{x}$ & & $\mathrm{x}$ & $\mathrm{x}$ & $\mathrm{x}$ & & & & $\mathrm{x}$ & $\mathrm{x}$ & $\mathrm{x}$ & $\mathrm{x}$ & \\
\hline Cradle-to-grave lifecycle visual mapping & $\mathrm{x}$ & $\mathrm{x}$ & & & $\mathrm{x}$ & & $\mathrm{x}$ & $\mathrm{x}$ & $\mathrm{x}$ & & & & $\mathrm{x}$ & $\mathrm{x}$ & $\mathrm{x}$ & $\mathrm{x}$ & \\
\hline Customer jobs-to-be-done & $x$ & & & & & $x$ & & $x$ & & & & & $x$ & $\mathrm{x}$ & $x$ & $\mathrm{x}$ & \\
\hline Customer value proposition & & & & & $\mathrm{x}$ & $x$ & $\mathrm{x}$ & & $\mathrm{x}$ & $x$ & & & & $x$ & $x$ & $x$ & $x$ \\
\hline \multicolumn{18}{|l|}{ Decision matrix } \\
\hline Ecosystem mapping & & $\mathrm{x}$ & $\mathrm{x}$ & $\mathrm{x}$ & & $\mathrm{x}$ & & & & & & & & & & $\mathrm{x}$ & \\
\hline Detailed empathy card & & & & & & $\mathrm{x}$ & & & & & & & & & & & \\
\hline Empathy maps & & $x$ & $\mathrm{X}$ & $\mathrm{X}$ & & $\mathrm{x}$ & & $\mathrm{x}$ & & & & & $\mathrm{x}$ & & & & \\
\hline \multicolumn{18}{|l|}{ Feedback grid } \\
\hline \multicolumn{18}{|l|}{ Feedback sheet } \\
\hline \multicolumn{18}{|l|}{ Five whys } \\
\hline Job-to-be-done insights & $\mathrm{x}$ & $\mathrm{x}$ & & & & & & $\mathrm{x}$ & & & & & $\mathrm{x}$ & & & $\mathrm{x}$ & \\
\hline Job-to-be-done outcomes & & $\mathrm{x}$ & & & & & & $\mathrm{x}$ & & & & & $\mathrm{x}$ & & & $\mathrm{x}$ & \\
\hline \multicolumn{18}{|l|}{ Keeping focused } \\
\hline Metric cascades & $\mathrm{x}$ & & $\mathrm{x}$ & $x$ & $x$ & $\mathrm{x}$ & $x$ & $x$ & $x$ & & & & $\mathrm{x}$ & $\mathrm{x}$ & $\mathrm{x}$ & $\mathrm{x}$ & $\mathrm{x}$ \\
\hline Personas & & & $\mathrm{x}$ & $\mathrm{x}$ & & & & & & & & & & & & & \\
\hline \multicolumn{18}{|l|}{ Pitching planning } \\
\hline \multicolumn{18}{|l|}{ Problem breakdown with the five Ws } \\
\hline Service blueprint & $\mathrm{x}$ & $\mathrm{x}$ & $\mathrm{x}$ & $\mathrm{x}$ & $\mathrm{x}$ & $\mathrm{x}$ & $\mathrm{x}$ & $\mathrm{x}$ & $\mathrm{x}$ & $\mathrm{x}$ & $\mathrm{x}$ & $\mathrm{x}$ & $\mathrm{x}$ & $\mathrm{x}$ & $\mathrm{x}$ & & $\mathrm{x}$ \\
\hline \multicolumn{18}{|l|}{ Storyboarding } \\
\hline Understanding your business & & & & & & & & & $\mathrm{x}$ & $\mathrm{x}$ & $\mathrm{x}$ & $\mathrm{x}$ & & & & $\mathrm{x}$ & \\
\hline Visual journey map - high level & $\mathrm{x}$ & $\mathrm{x}$ & $\mathrm{x}$ & $\mathrm{x}$ & $\mathrm{x}$ & $\mathrm{x}$ & $\mathrm{x}$ & $\mathrm{x}$ & & & & & $\mathrm{x}$ & & & & \\
\hline Visual journey map - detail level & $\mathrm{x}$ & $\mathrm{x}$ & $\mathrm{x}$ & $\mathrm{x}$ & $\mathrm{x}$ & $\mathrm{x}$ & $\mathrm{x}$ & $\mathrm{x}$ & & & & & $\mathrm{x}$ & & & & \\
\hline
\end{tabular}




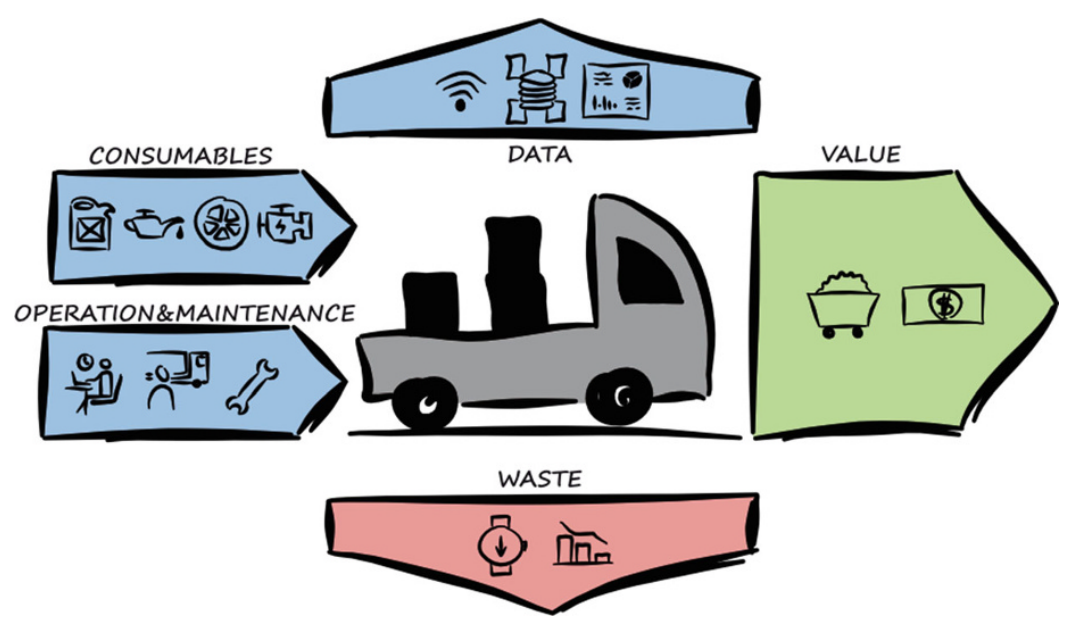

Fig. 3.2 An example of an avatar map (illustration by Annick Holland, adapted from West et al., 2020a)

avatar can be the focus of a journey mapping exercise or a lifecycle analysis. Here short- or longer-term insights can be obtained from the visual tool (Fig. 3.2).

\section{Business Model Canvas}

This is a great tool for describing and sharing your business model with others. Always start with the value proposition and connect it to customer segments. Remember that you will need more depth than you see on the canvas itself.

With services you will need to learn to integrate different revenue models into value propositions to support a specific segment. Cost models are dependent upon what you do and what you outsource (and here you could outsource to your customers) (Fig. 3.3).

\section{Business Process Mapping}

Business process mapping allows you to understand the steps that a process must go through from start to finish. It provides a clear view of what is happening and who should take the lead. It is closely related to a service blueprint and a journey map.

A business process map should be read left to right and should describe who is involved in the process and their roles. You may like to link this to jobs-to-be-done and empathy maps or personas to get deeper insights. Remember first to create an overview process map, and then create the detailed maps. It is best done with a long whiteboard and many Post-it notes (Fig. 3.4).

\section{Case/Actor Matrix}

This tool helps you understand who is involved in different situations. It shows you quickly and in one form who takes the lead and who are the other actors involved. 


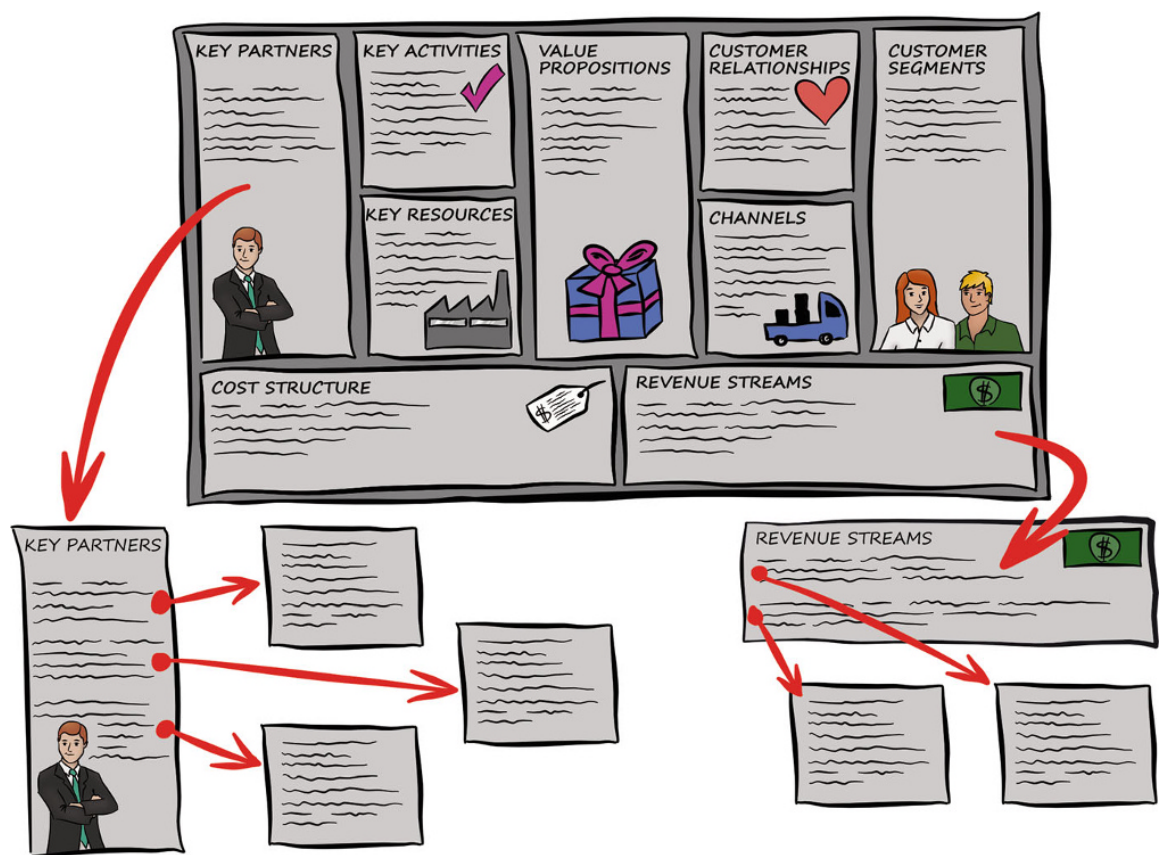

Fig. 3.3 Depth is often needed to understand the business model in sufficient detail (illustration by Annick Holland, adapted from Osterwalder \& Pigneur, 2010)

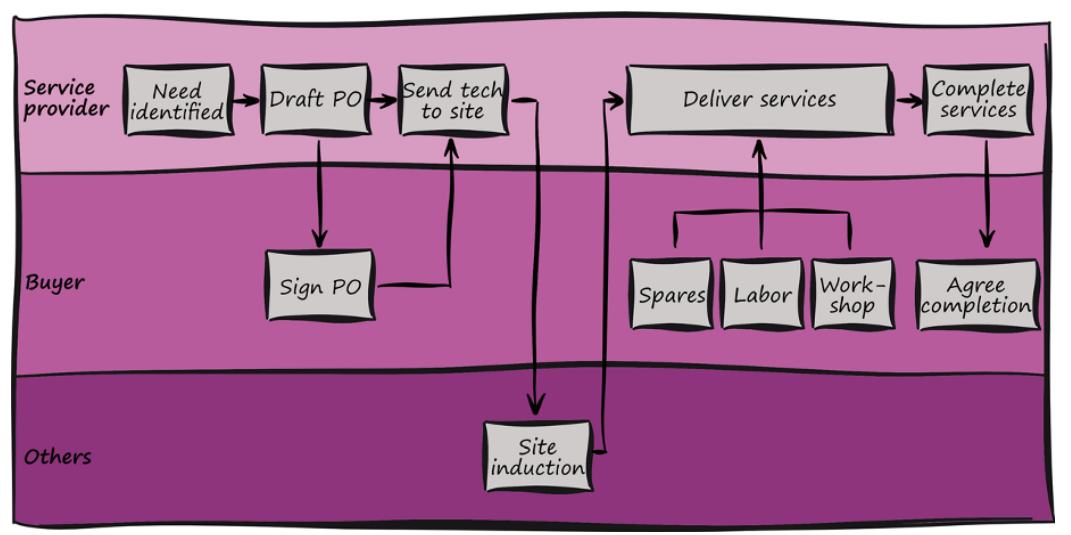

Fig. 3.4 An example basic business process map (illustration by Annick Holland, adapted from Tseng et al., 1999)

This tool can be powerfully insightful for service, as individual service events are all involved and based on interactions between individuals. 


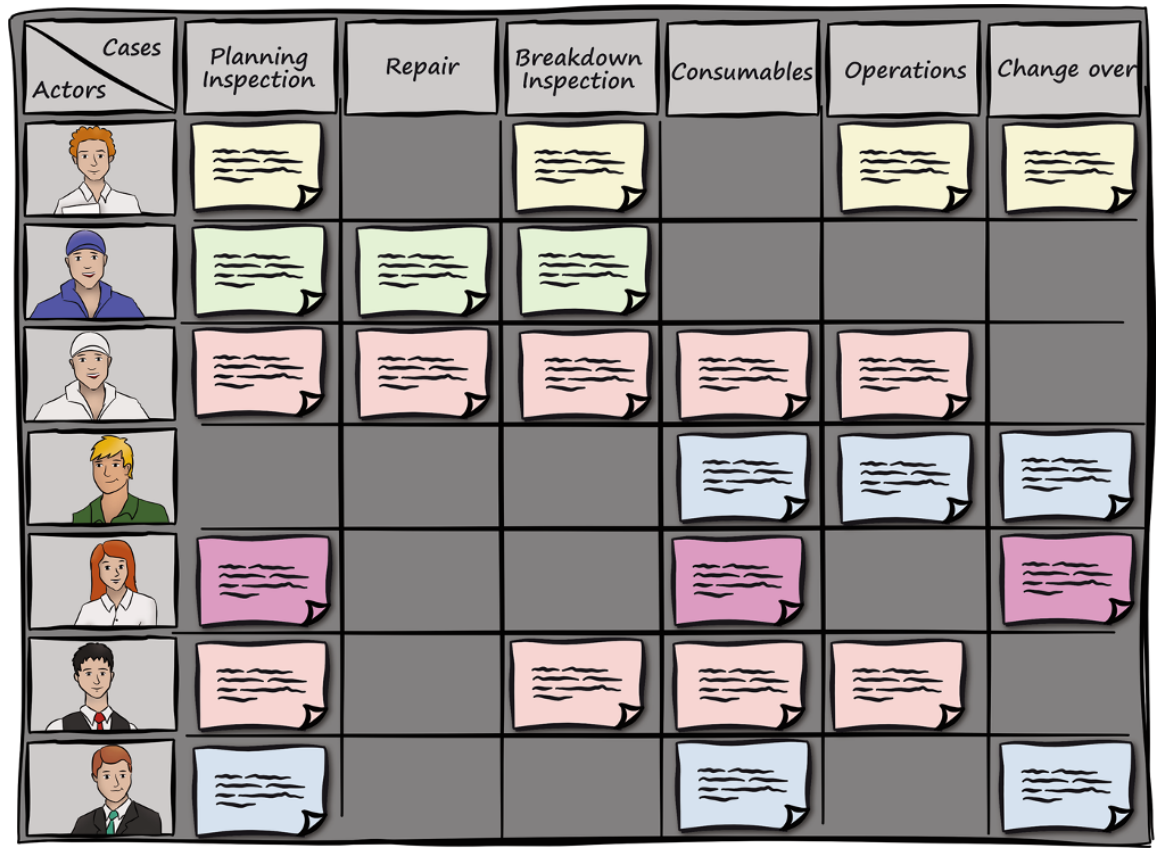

Fig. 3.5 An example of a case/actor matrix (illustration by Annick Holland, adapted from Stoll et al., 2020)

Make the matrix visual, and remember that for every firm this will be different. On aggregate, you will see common roles taking the lead responsibility. You might like to spit the actors into suppliers and customers, and then create a detailed journey map for every case (Fig. 3.5).

\section{Context Map}

The context map forces you to identify the dimensions of your problem or opportunity space. Using the context map, you are limited to eight dimensions; this is hard to deal with and focuses your attention on the real issues. Several context maps can be created from different points of view. However, the focal aspect must always be placed in the center (Fig. 3.6).

\section{Cradle-to-Grave Lifecycle Visual Mapping}

The cradle-to-grave lifecycle visual mapping tool helps you as manufacturers to understand the whole life of your equipment or products. It creates a storyboard of what each avatar will "experience" over its entire life. However, the avatar's lifecycle is not limited by the PLM cycle defined by the manufacturer but that defined by the asset owner. For example, the B52 bomber is still in operation today even though it is 70 years since it first flew. 
Fig. 3.6 An example of a context map to help you focus on the problem (illustration by Annick Holland, adapted from Carleton et al., 2013)
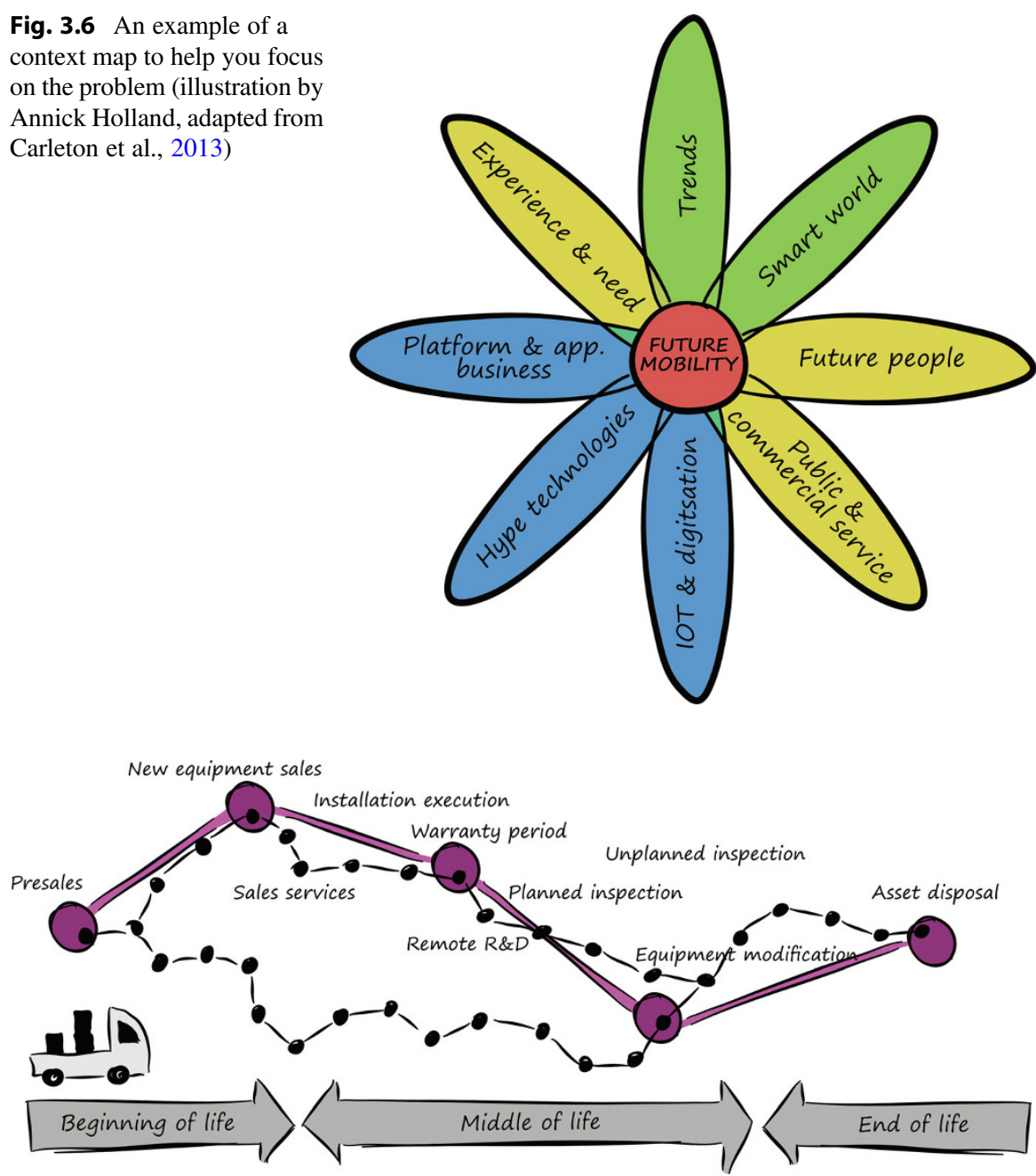

Fig. 3.7 An example of a cradle-to-grave lifecycle visual map (illustration by Annick Holland, adapted from West et al., 2020a)

The tool has three lifecycle phases and defines all the different services required to keep the avatar optionally functional for the owner. The tool can help you develop the total cost of ownership (TCO) based on the required activities and services. The model is best completed on a large whiteboard with customers, as there will be many activities that the manufacturer is unaware of (Fig. 3.7).

\section{Cradle-to-Grave Lifecycle Map}

Cradle-to-grave lifecycle activity mapping follows on from the visual mapping. Here, the purpose is to understand, on an annual basis, the costs associated with 


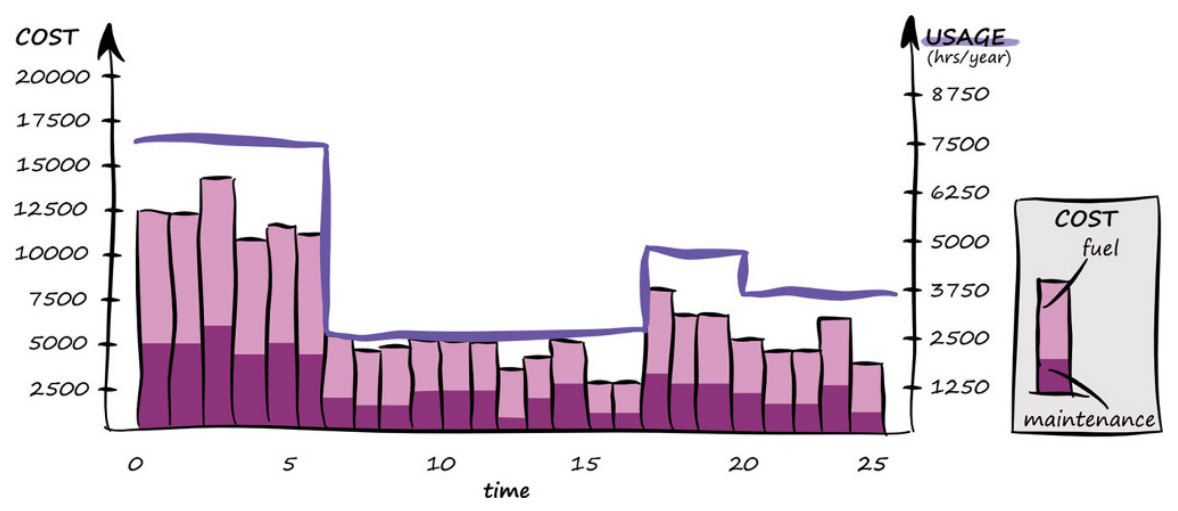

Fig. 3.8 An example of a cradle-to-grave lifecycle map (illustration by Annick Holland, adapted from West \& Pascual, 2015)

the operations and maintenance of the machine or its avatar, to build up its total cost of ownership (TCO).

This tool will help you demonstrate to your customer the cost breakdown of the equipment and show the anticipated maintenance budget required over its full operational life. You will also learn from the customer about their costs, some of which may be hidden from you. Again, this is best when completed with a customer, and it is essential to understand the customer's cost drivers for the calculation. It can be done in the development phase of a new product to understand the total cost of ownership (TCO) or during the midlife phase to help with the assessment for an upgrade (Fig. 3.8).

\section{Customer Jobs-to-Be-Done}

Even trying to understand the job that a customer has to do can be very complex, it is essential for you to offer them the appropriate services. This is important, particularly where a product can have different applications in different industries, and critically some aspects (e.g., the value in use) can be very different, depending upon its actual application.

The customer job-to-be-done tool was developed to help you capture what is going on in a simple visual way, as reported in the example of Fig. 3.9. The visualization shows the core process and the supporting activities, linking them to business metrics. This tool is complementary to the avatar tool. Each step provides inputs to the next one; each needs inputs and creates an output. The steps need to have supporting activities and performance metrics or key performance indicators. The right-hand side of the tool is used to describe simply what the jobs-to-be-done are for the overall business. The statement should be straightforward, based on what described the purpose or mission of the business. 


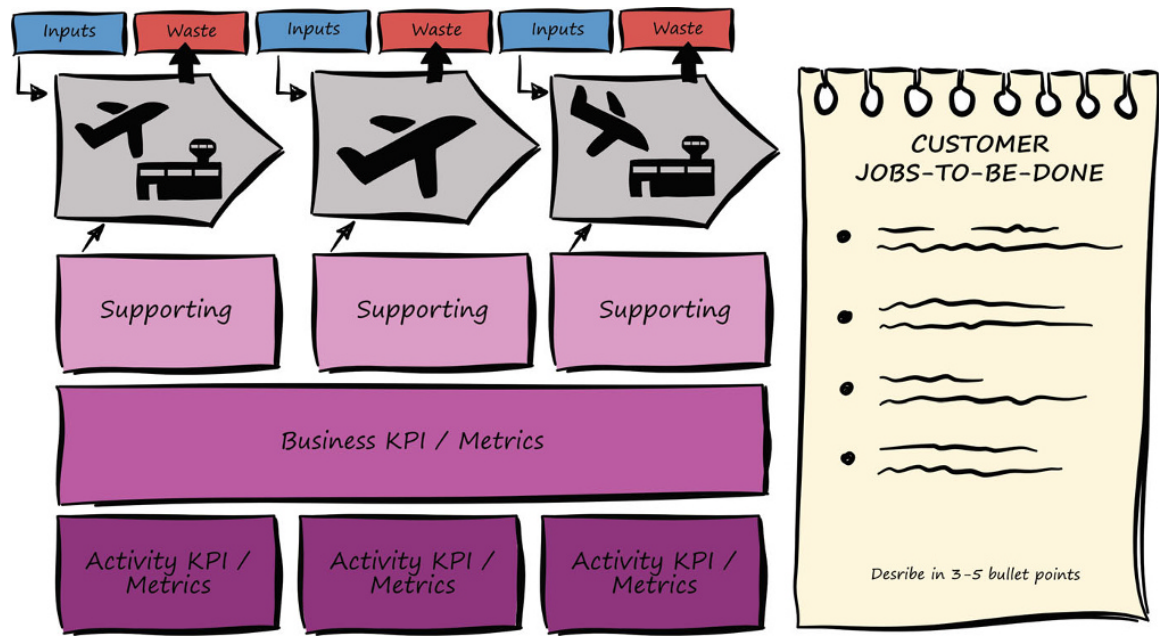

Fig. 3.9 An example of a customer jobs-to-be-done (illustration by Annick Holland, adapted from West et al., 2018b)

\section{Customer Value Proposition}

The customer value proposition is a very powerful tool to help understand what you are actually delivering to your customers and why they like it.

Use the customer side to explain the problems in a simple form. Then, fill in the solution description to describe what you are doing today. Now, you can begin to imagine new ways to fulfill the customer's problem description (more than one possible solution is always possible). Invent some very different ways to deliver it: consider a do-it-yourself model, models where you share the work with customers in new ways, or one where you deliver all of the services for them. The more solutions you are able to come up with, the better! You can then plot them out on a two-by-two decision matrix to assess which ones you will test with your customers. Remember not all customers are the same (Fig. 3.10)!

\section{Decision Matrix}

A decision matrix is a basic two-by-two analysis tool. The two axes are the basis of the decision-making and allow clustering and grouping of problems, ideas, or solutions.

Often the vertical axis is based around "value" or "importance" and the horizontal axis on "feasibility" or "effort." This helps you to make decisions based on these dimensions as well as share the decision-making process with mixed teams (Fig. 3.11).

\section{Ecosystem Mapping}

Ecosystems can be very complex to build and understand. However, they are very useful, as they provide essential insights into a firm's formal and informal processes. 


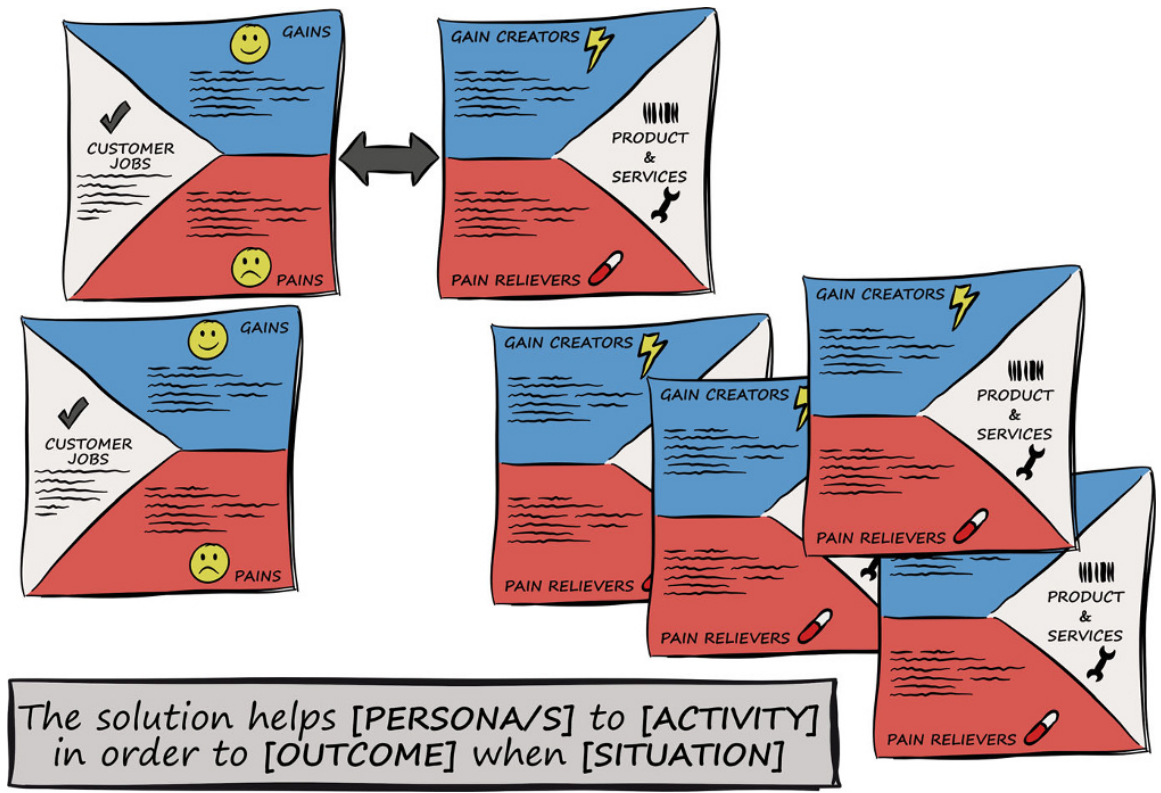

Fig. 3.10 Use the value proposition to help describe customer problems and create possible solutions (illustration by Annick Holland, adapted from West et al., 2018b)

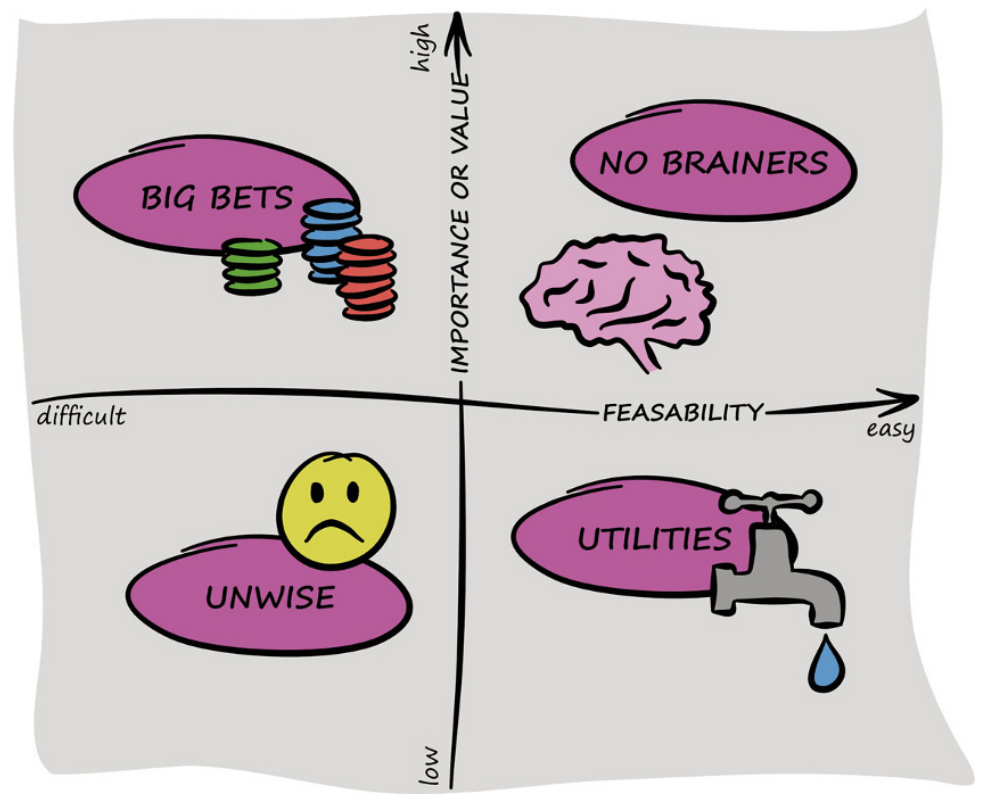

Fig. 3.11 A sample decision matrix (illustration by Annick Holland, adapted from IBM, 2018) 


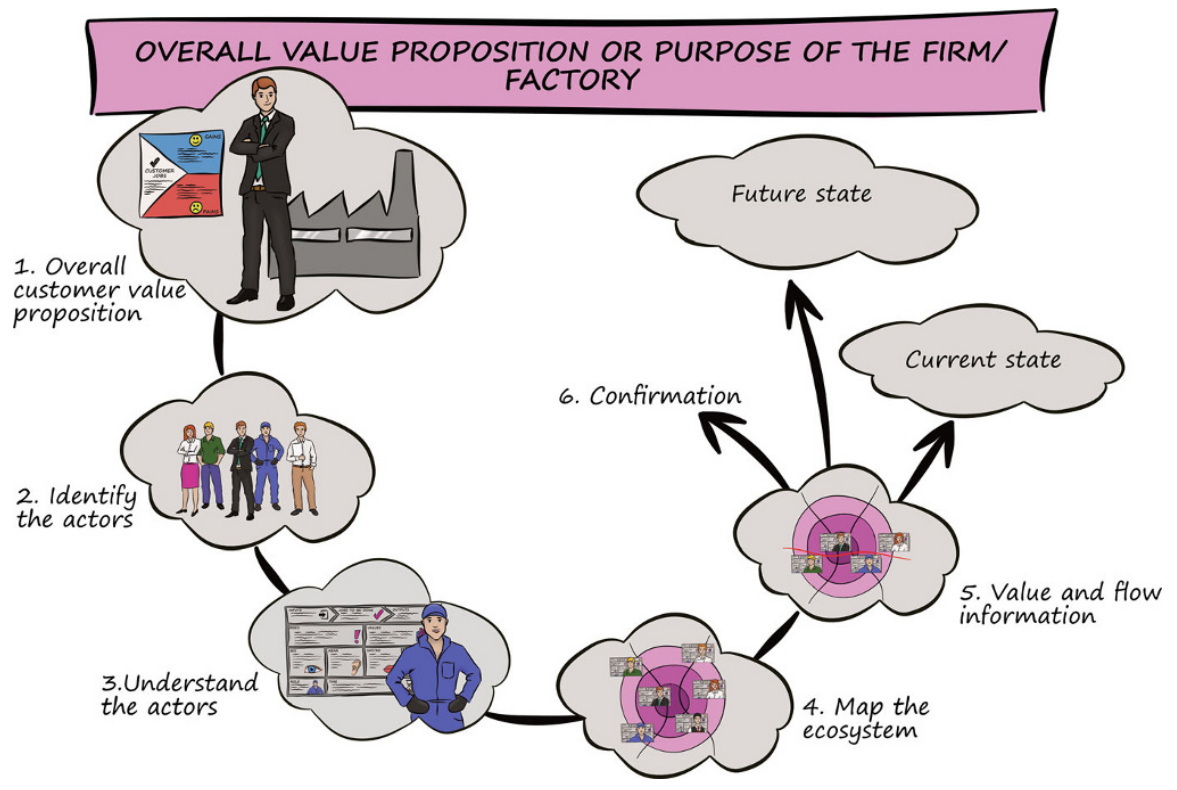

Fig. 3.12 Learning to navigate an ecosystem (illustration by Annick Holland, adapted from West et al., 2018a)

That's why ecosystem mapping can be essential to understand all the dimensions of your problem.

First, identify the overall customer value proposition, job-to-be-done, or purpose of your customer's business. Then, describe all the actors in the whole process; often, this takes several iterations as not everyone knows all of the actors, and, even if they do, you need different perspectives to get a full picture. Using the detailed empathy cards, describe the actors in as much detail as necessary. Then, place them on a board, and start to link up the value and information flows using string or tape. You may find it helpful to integrate the avatars in the ecosystem. You can then confirm the current state as well as start to build alternative future states. Building the ecosystem as a team is a chance to gain a joint understanding of it (Fig. 3.12).

\section{Empathy Card}

The detailed empathy card is a way of understanding the motivation of the people involved in the ecosystem. This can be very powerful, both in developing change management initiatives and when trying to sell a new concept of service to customers.

As with a basic empathy card, it considers the four key aspects of "see, hear, say/do, and think/feel." It also examines what people consider as "pains" and "gains." Additionally, it asks what the inputs are to their job-to-be-done and what the outputs are. Finally, it captures basic information on their role and the time they have (Fig. 3.13). 


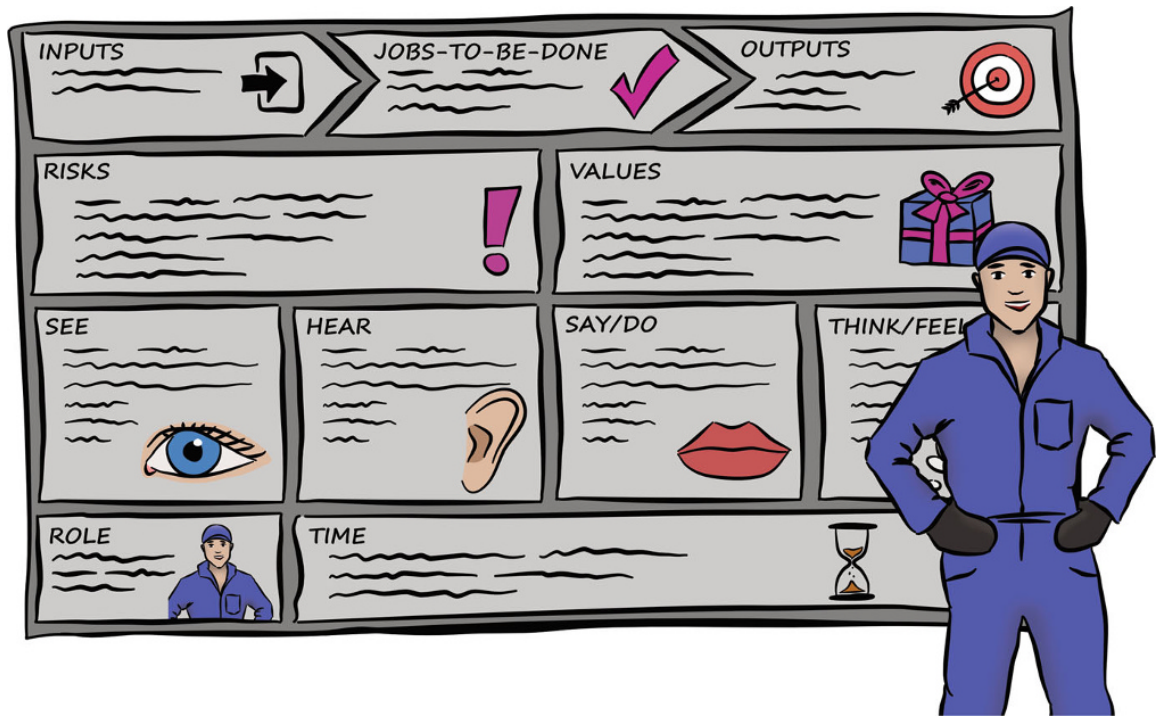

Fig. 3.13 A template for a detailed empathy card (illustration by Annick Holland, adapted from West et al., 2018a)

\section{Empathy Maps}

Empathy maps are a great way to get into people's shoes and start to understand and analyze the world from their perspective.

It takes time to get used to using this tool. It's a good way to understand the situation and learn how to react - this is why it is called "empathy." Detailed empathy cards are another very useful tool to help you go into more depth about particular people (Fig. 3.14).

\section{Feedback Grid}

The feedback grid allows you to get suggestions and comments from a group of people quickly. Four simple questions can be answered on Post-it notes to provide you with new insights that you can later put into action (Fig. 3.15).

\section{Feedback Sheet}

When developing new services (based on the blueprint or actual services), it is good to get feedback. Using this sheet allows you to do this in a structured way. Moreover, it supports the adoption of detailed journey mapping, and the two tools can be used together.

The test scenario describes the situation you are evaluating and what you are looking for. The reflections should be a mix of yours and the person you are testing. Try to keep it visual. This is best done using pen and paper (Fig. 3.16). 


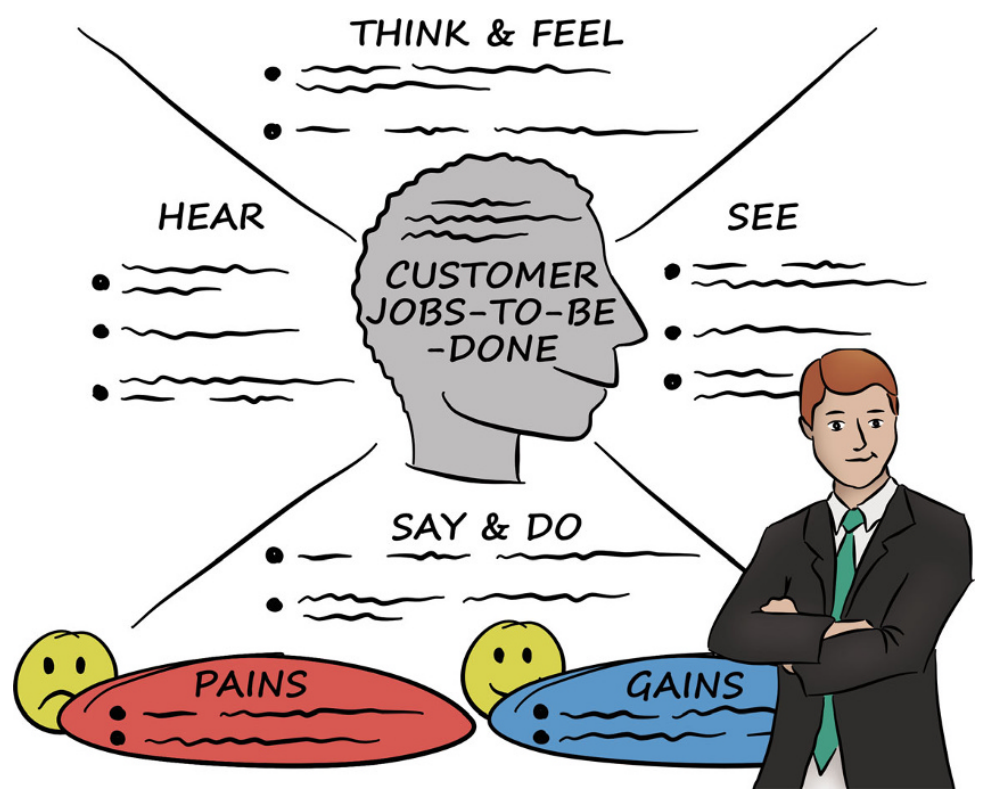

Fig. 3.14 An example of a basic empathy map (illustration by Annick Holland, adapted from Meinel \& Leifer, 2015)

Fig. 3.15 An example of a feedback grid (illustration by Annick Holland, authors' work)

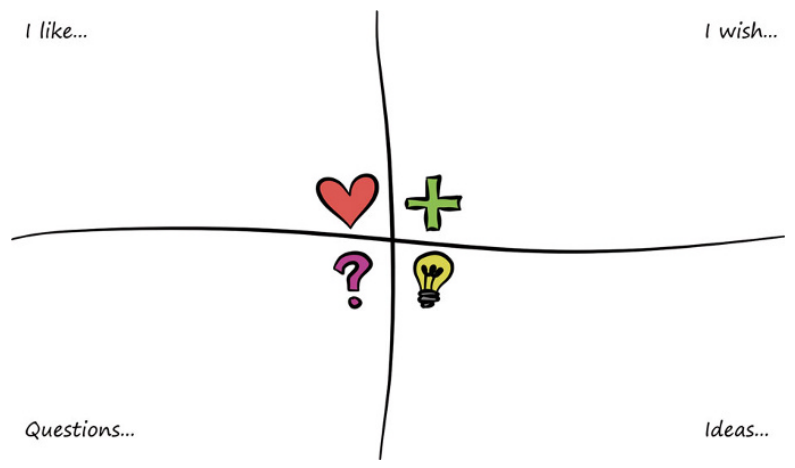

\section{Five Whys}

The five-why technique is used to get to the root cause of a problem. It is closely related to the five Ws. You should use them jointly when you are trying to understand a problem in depth. Too often, we do not get to the root cause of a problem but rather only consider the symptoms (Fig. 3.17).

\section{Job-to-Be-Done Insights}

Job-to-be-done insights allow you to get a detailed understanding of people and their actions. Based on the three main statements - when..., I want..., so I can... - it is a 


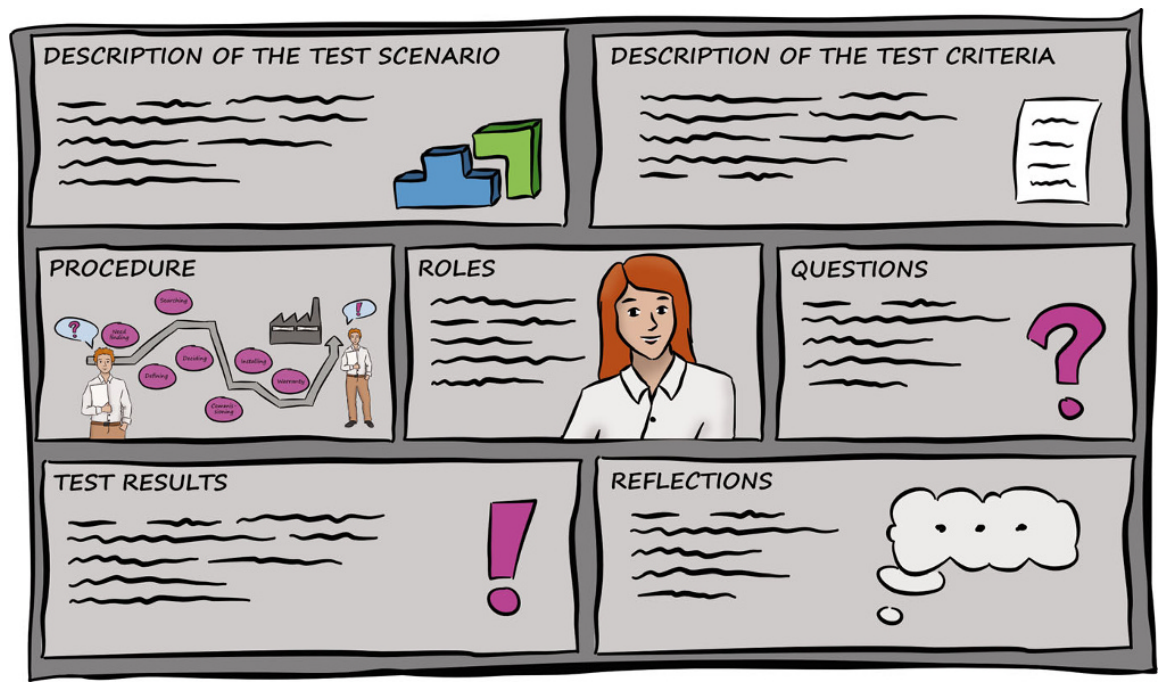

Fig. 3.16 An example of a feedback sheet (illustration by Annick Holland, adapted from Kumar et al., 2020)

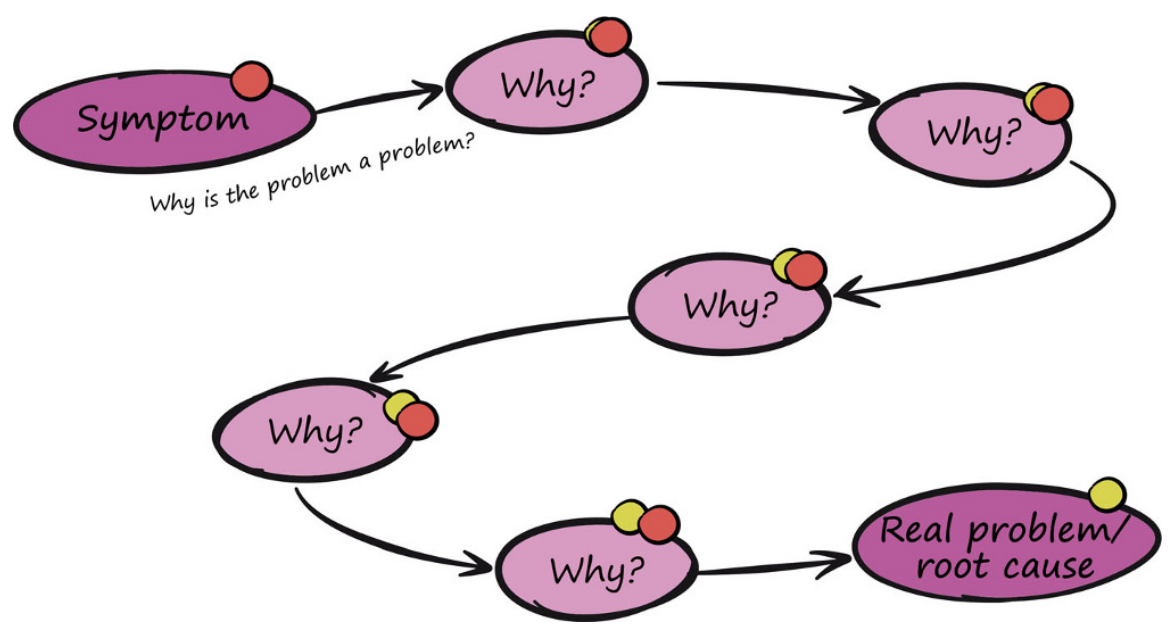

Fig. 3.17 Root cause analysis with five Ys (illustration by Annick Holland, adapted from Pojasek, 2000)

very simple approach to building a simple process and understanding where you as the service provider could help your customer.

It works as well within your organization as in other businesses (Fig. 3.18). 


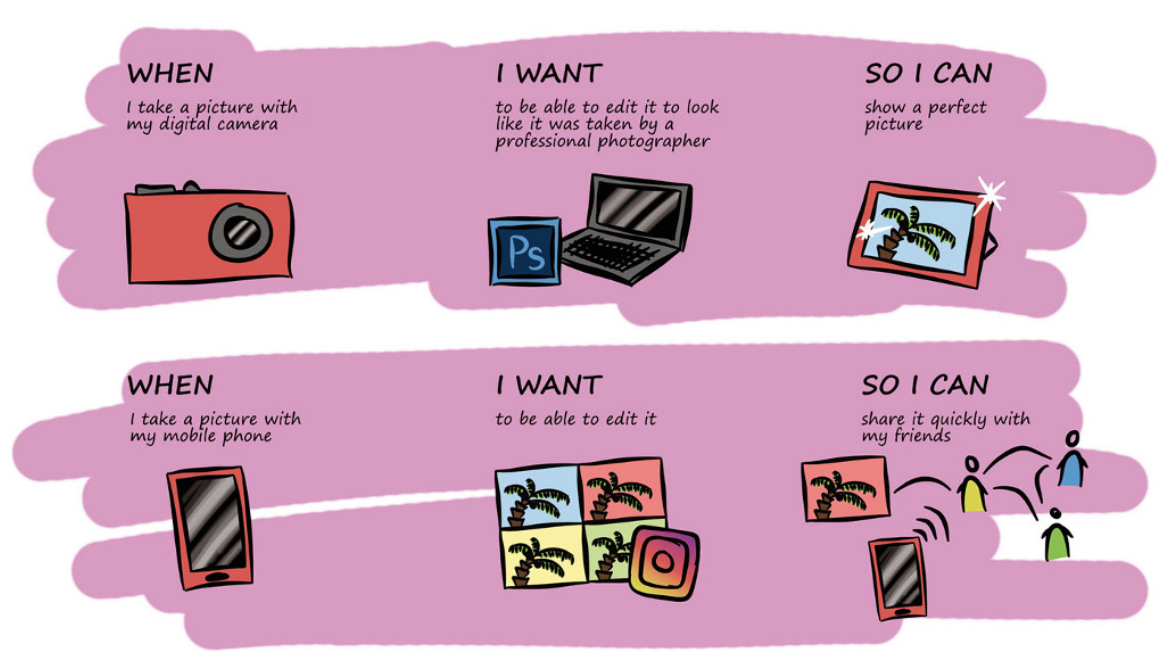

Fig. 3.18 Job-to-be-done insights (illustration by Annick Holland, adapted from Christensen et al., 2016)

\section{Job-to-Be-Done Outcomes}

Job-to-be-done is a great way to help make the innovation actionable. Too often, we just "score" innovation. Conversely, with this approach, you can get into the detail of what is being done through building a customer process map - considering the core process steps and the supporting services. From that understanding, it is possible, using the formula, to build a clear outcome that is statement based. Using the outcome statement, you can then ask actors if they are satisfied with it and verify how important it is for them.

The results of satisfaction and importance can also be plotted on a two-by-two decision matrix. You can then build a roadmap that helps you to identify what to focus on first and what you could do later. Finally, it shows you where you overdeliver and where you might be able to reduce cost (Fig. 3.19).

\section{Keeping Focused}

Keeping focused means understanding what your core services are and what are the "other services". It is important to track both, as some of the "other services" you may want to stop offering or redefine.

In both cases, you need to use customer data (e.g., sales volumes and margins) to provide you with the input (Fig. 3.20).

\section{Metric Cascades}

The metric cascade is helpful to understand how you contribute to the customer's outcome (or not). There is often more than one way to provide lower costs to the customer, and this method can help you see that your costs may be important, but they might not represent a major cost to your customer's operations. Moreover, developing a cascade can provide you with an understanding of what you do and 
a

CUSTOMER PROCESS MAP

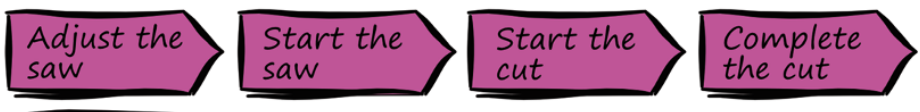

Maintain the saw (ad hoc process)

Ensure safety (continious process)

b

FORMULA
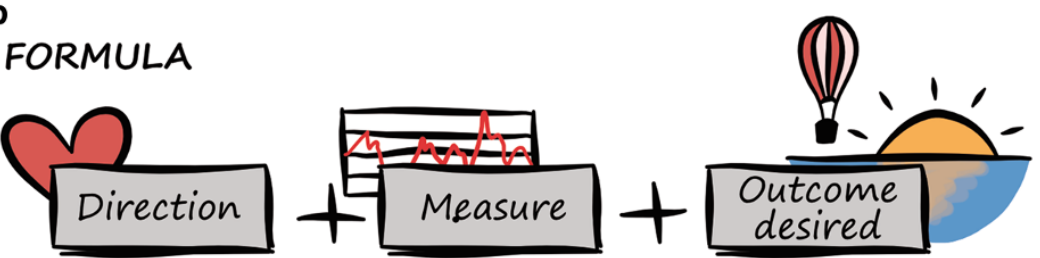

Minimize the likelihood of debris blowing in the person's eyes

c

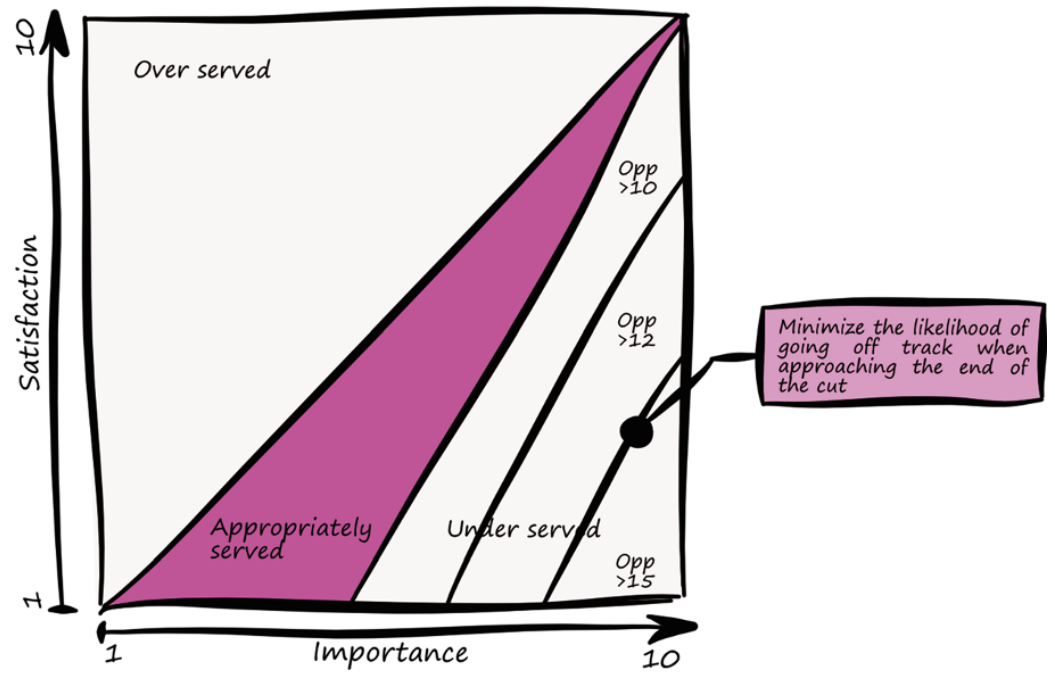

Fig. 3.19 Job-to-be-done outcomes (illustration by Annick Holland, adapted from Ulwick, 2002 and 2005)

affect and what it might do for your customer - there is always more than one way to skin a cat. This method can work well with understanding "customer jobs-to-bedone" and can help provide detailed insights into the operation (Fig. 3.21).

\section{Personas}

Personas give you a wider and deeper view of an actor than empathy maps. Therefore, an empathy map can be a good starting point to allow you to build a persona. You can start from it to create a detailed persona that allows you to get 


\section{Keep focused on what you can do}

\section{Top 5 services}
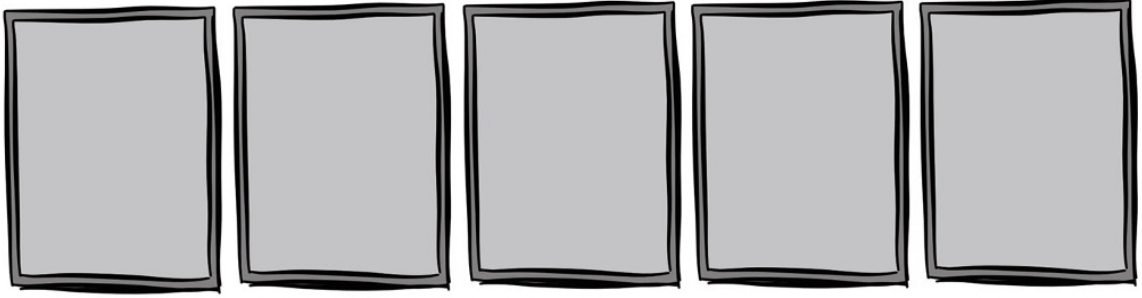

\section{Other services}
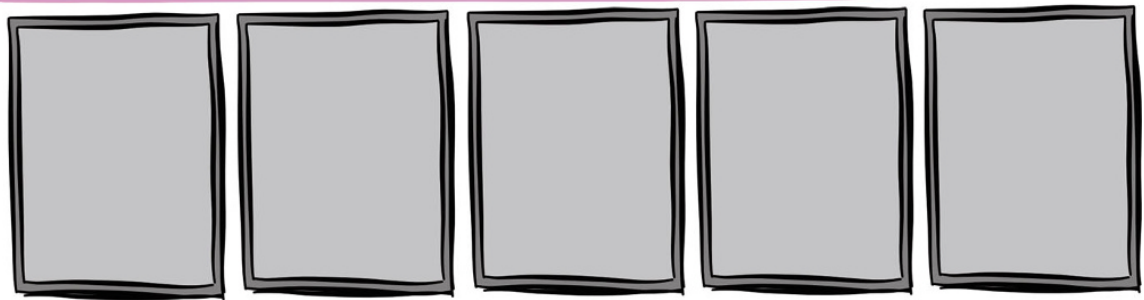

Fig. 3.20 A template to help keep focused (illustration by Annick Holland, adapted authors' work)

under the skin of an actor to understand more about what motivates them and how they can contribute (Fig. 3.22).

\section{Pitching Planning}

Making an impactful pitch is helpful to "sell" your idea. This seven-slide model can help you put your thoughts together so that you do not get lost in the problem's details and the solution. Depending on your situation, you can replace slides (e.g., the business model slide may not always be required). Pitching is closely related to the storytelling tool, as it adopts a simple story line with focus, to help you to end up with less conflict when it comes to reaching an agreement with colleagues and managers. To make this tool more efficient, the intro slides should contain the purpose of the pitch (e.g., why are we here?), while the key messages and the feedback should be on the slides that you are using - not hidden in the text but clearly presented on the slides. Moreover, the summary slide should include a statement that confirms the agreement. After the meeting, issue the slides as notes and, in pen, state the agreement that was reached. Adjust the structure depending on the situation - always confirm the purpose of the pitch, and provide a clear view of the next steps. Rather than taking detailed minutes, attach the final agreement to the pitch, and share it quickly with the team (Fig. 3.23). 


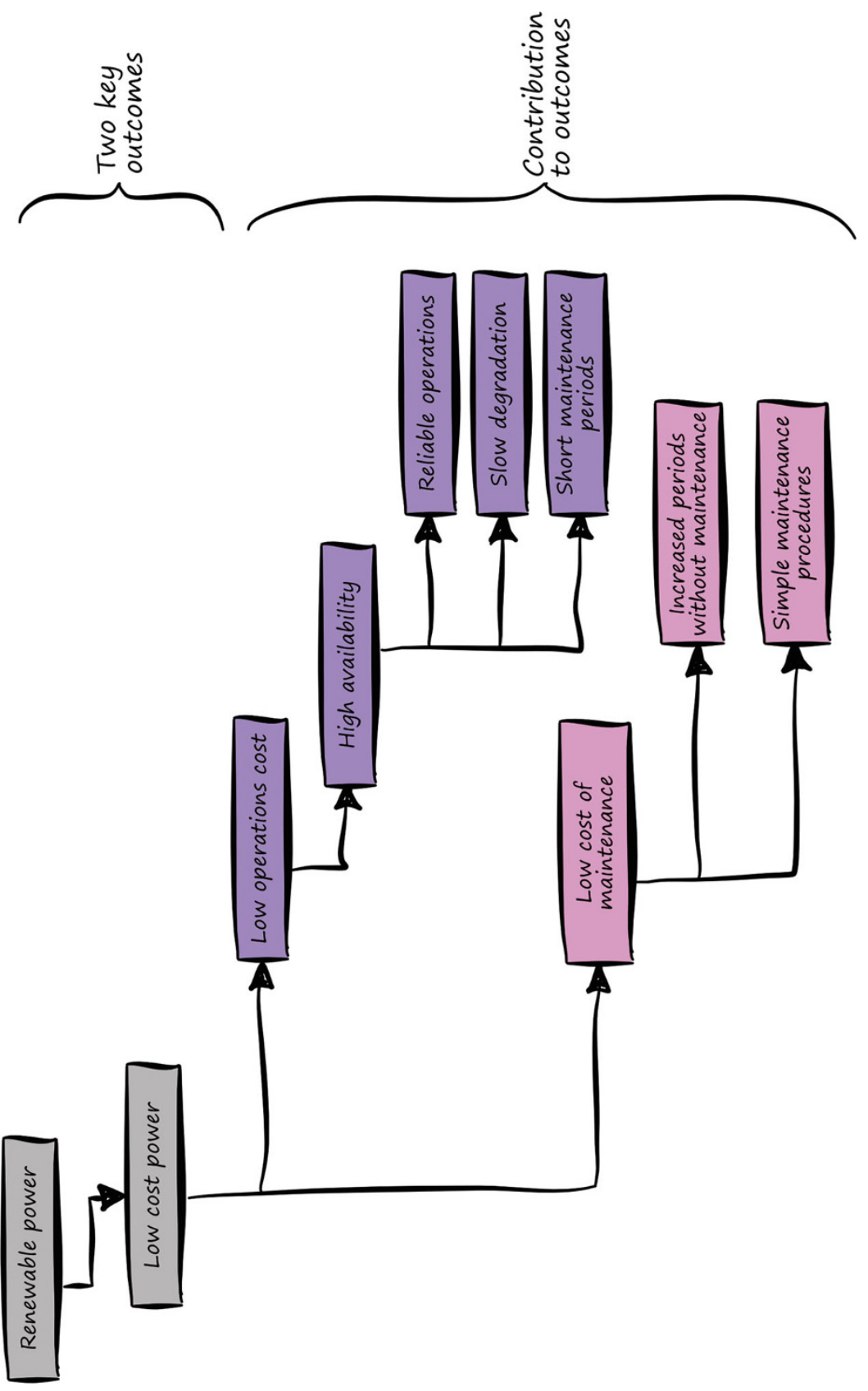

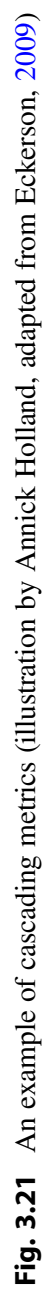




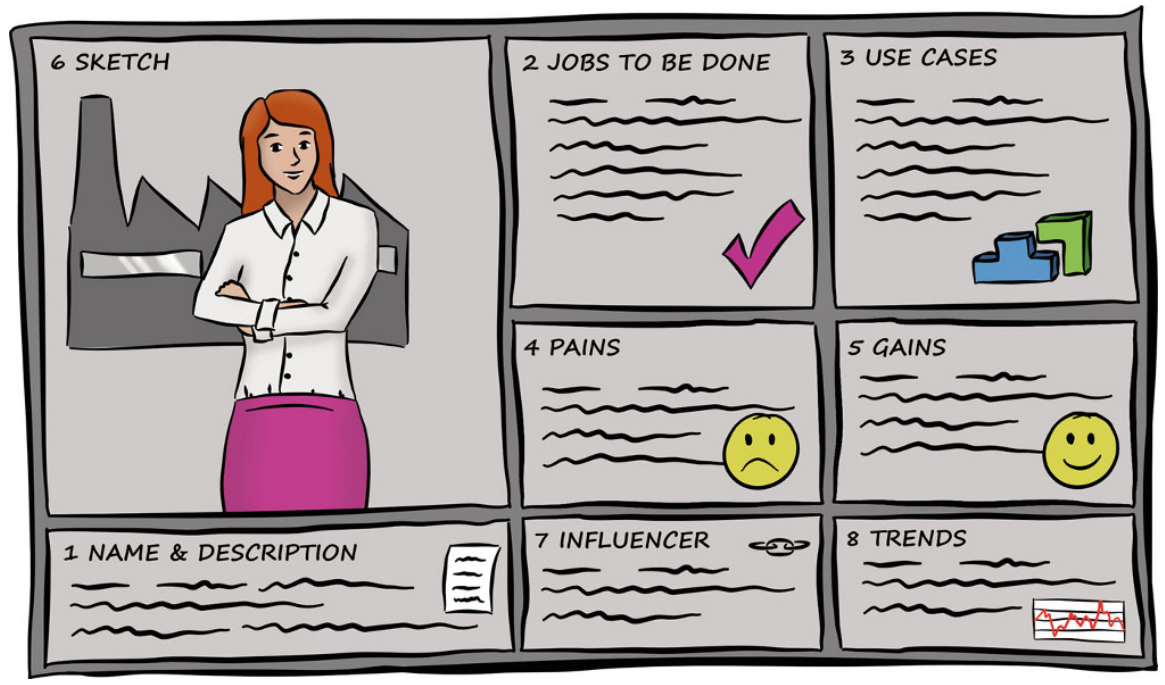

Fig. 3.22 An example of a persona (illustration by Annick Holland, adapted from Harniess \& Harniess, 2020)

\section{Problem Breakdown with the Five Ws}

Using the five Ws provides a comprehensive analysis of many problems. The tool is complementary to the five-why tool and gives you more contextual information on a problem (Fig. 3.24).

\section{Service Blueprint}

The service blueprint can help you to understand the connections between different individual tasks. You can get insight into the tasks and people who are normally hidden from view. Moreover, it allows you to sequence the service journey as you imagine or design it. For simplicity, it is best to use the same template for a service blueprint (the planned or designed service) as well as journey mapping (actual state).

You need to understand the use case (e.g., the service and its value proposition) and the involved stakeholders (direct and indirect). Adding high-level phases to the blueprint always helps develop better understanding. You should always start "too early" and end well after the service has been delivered. Graphics really bring the blueprint alive and make it easier to understand (Fig. 3.25).

\section{Storyboarding}

Stop before you work in PowerPoint to create a presentation, and first create a storyboard. By doing this, you will improve the clarity of your communication. By creating a simple visual narrative supported with some text, you will have more impactful and more clearly communicated messages. Focus on the "beginning," "middle," and "end" (Fig. 3.26). 

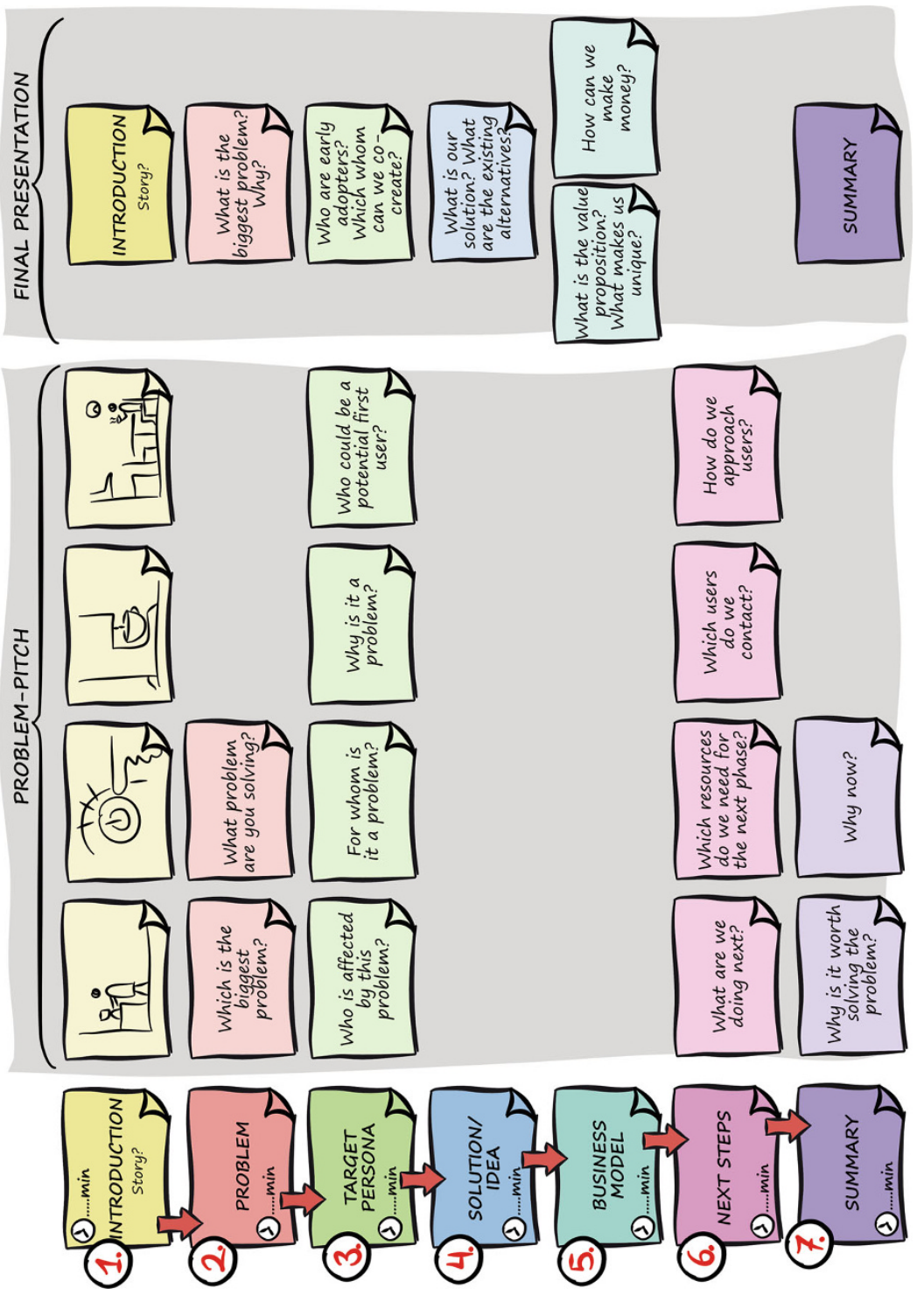

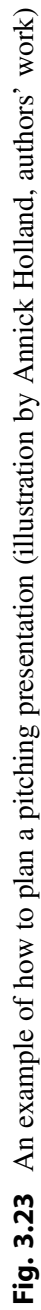




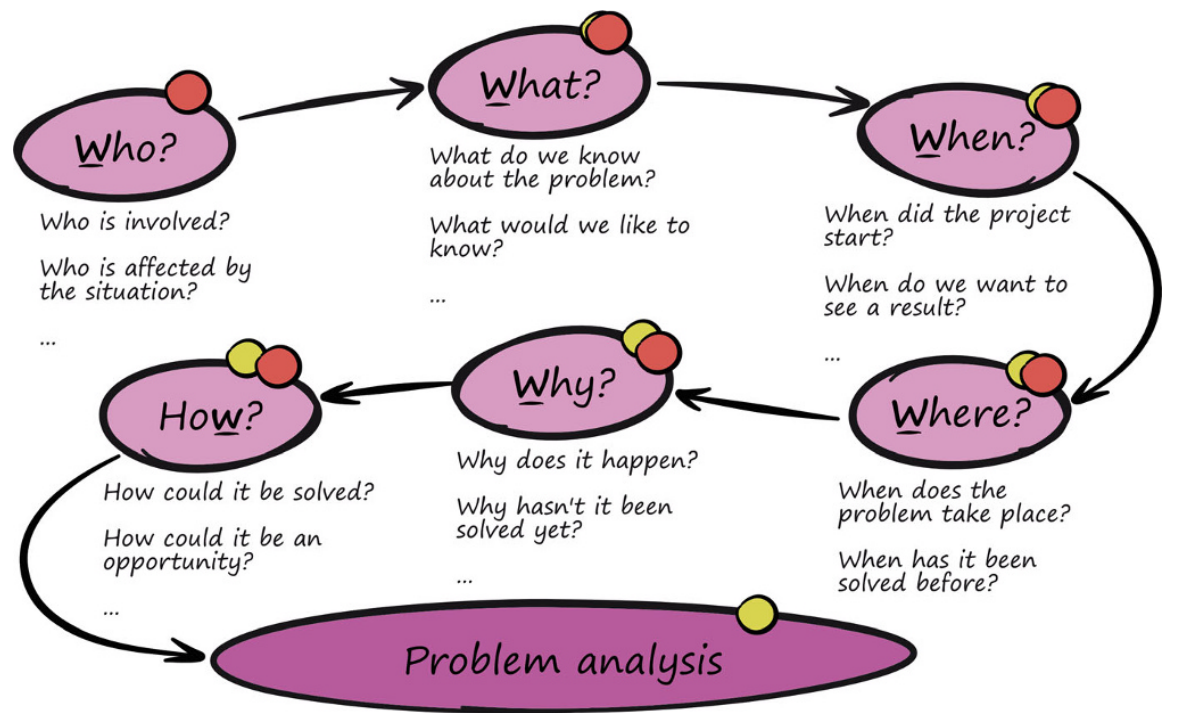

Fig. 3.24 Problem breakdown (illustration by Annick Holland, adapted from Wikipedia, 2020)

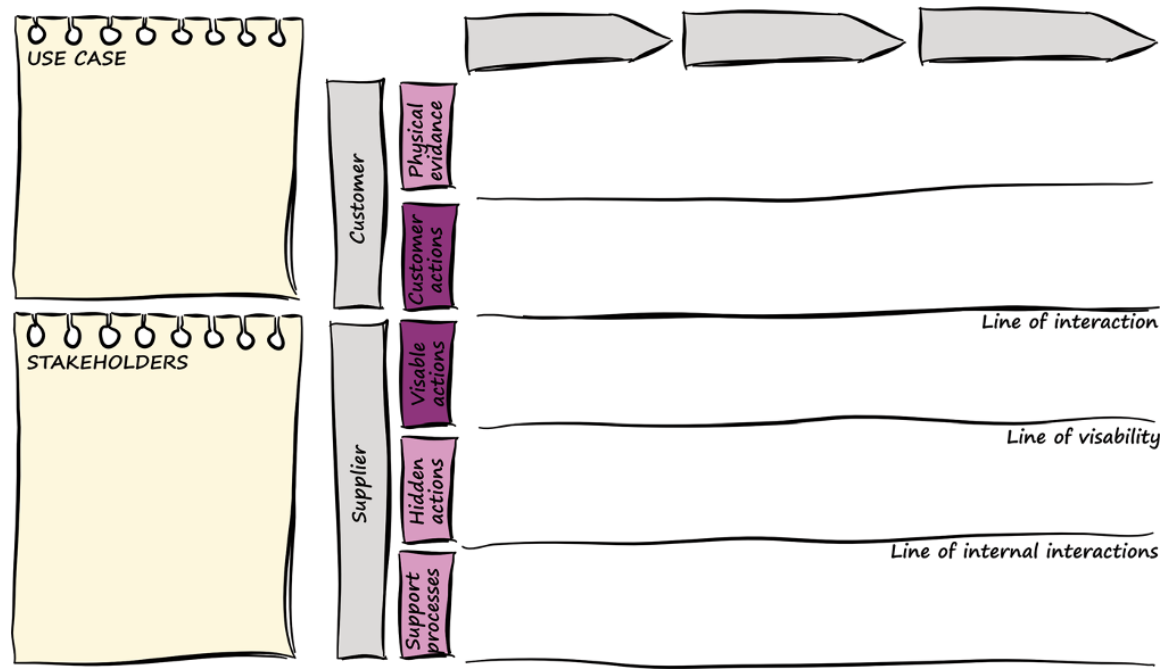

Fig. 3.25 An example of a service blueprint template(illustration by Annick Holland, adapted from Lynn, 1984)

\section{Understanding Your Business}

It is important to understand your business, and this tool allows you (with your team) to do this in more depth and with more objectivity. It supports the business model canvas tool. As a team, this model helps you to share what the firm does, why, and 


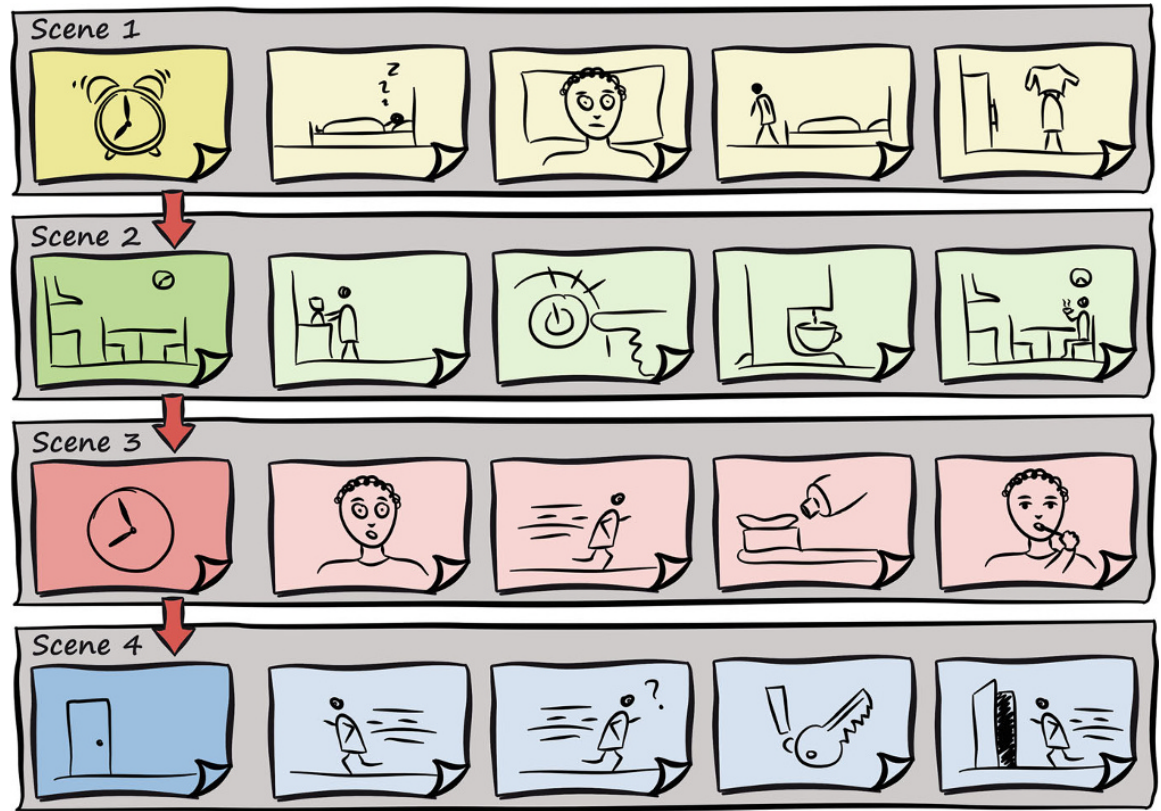

Fig. 3.26 An example of storyboard planning (illustration by Annick Holland, adapted from Wikström et al., 2013)

how. Often, we found it necessary to make two loops to get a shared understanding (Fig. 3.27).

\section{Visual Journey Map: High Level}

When a visual journey map is drawn, it allows you to understand the problem better at a high level before you dive into the details. A whiteboard with Post-it notes is often a good way to create this kind of map. Very quickly, you start to see and understand a problem from many perspectives.

This can form the first part of a detailed journey map for a customer. In addition, it can help you to understand the equipment lifecycle from the asset management perspective rather than the manufacturer's perspective. To make it really effective, every touchpoint here should have a value proposition clearly defined. Moreover, every person identified (customer and supplier side) should have an empathy card or a persona developed, to further deepen the insights (Fig. 3.28).

\section{Visual Journey Map: Detail Level}

By detailing out an individual journey map, you will learn what people like and, importantly, dislike about the services you deliver. Therefore, this is a tool that allows you to get direct and actionable feedback from a customer and learn more about how they act and behave. 


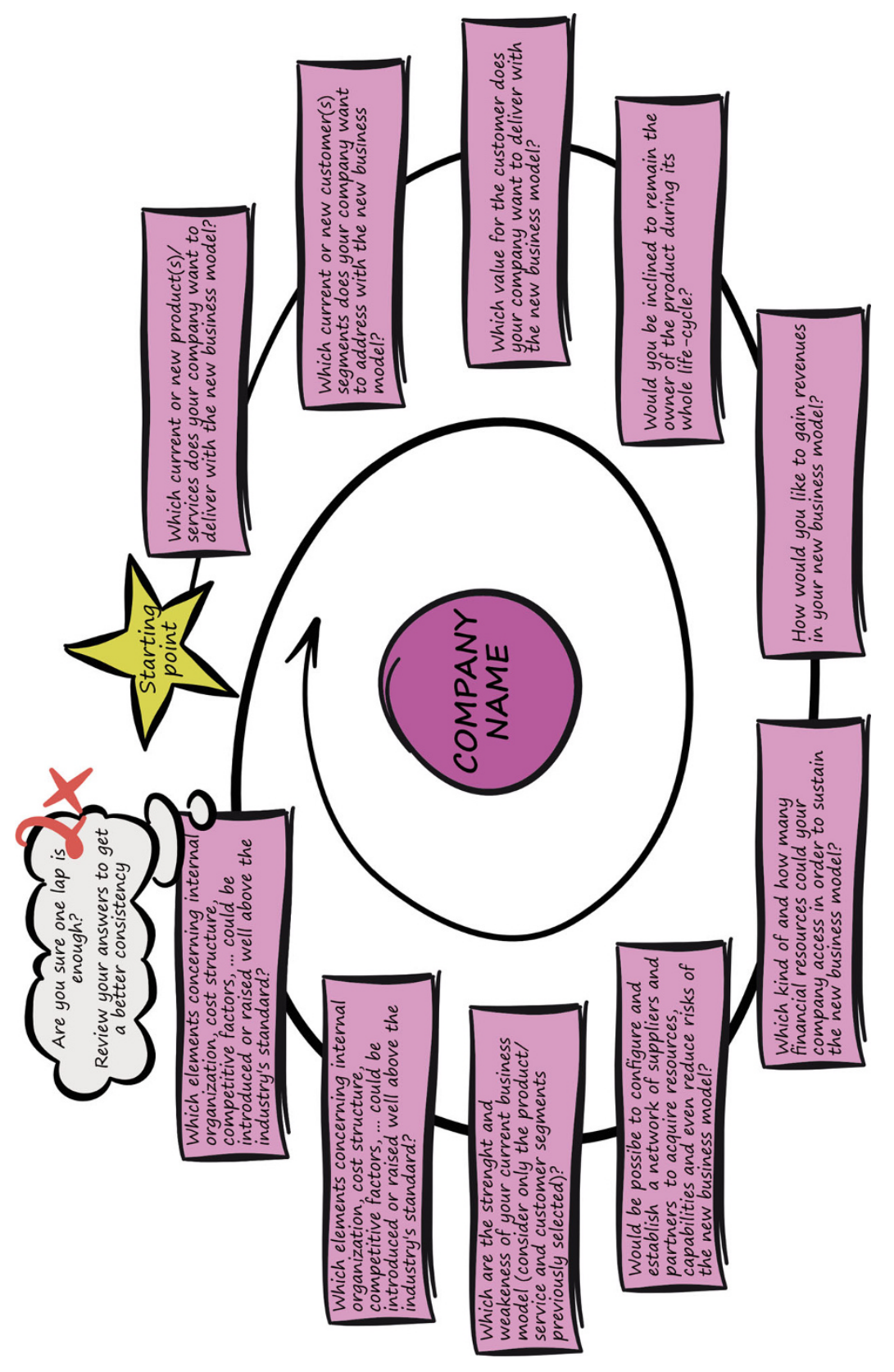

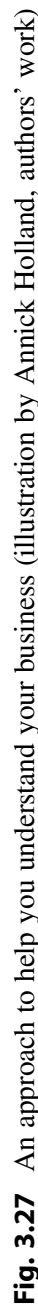




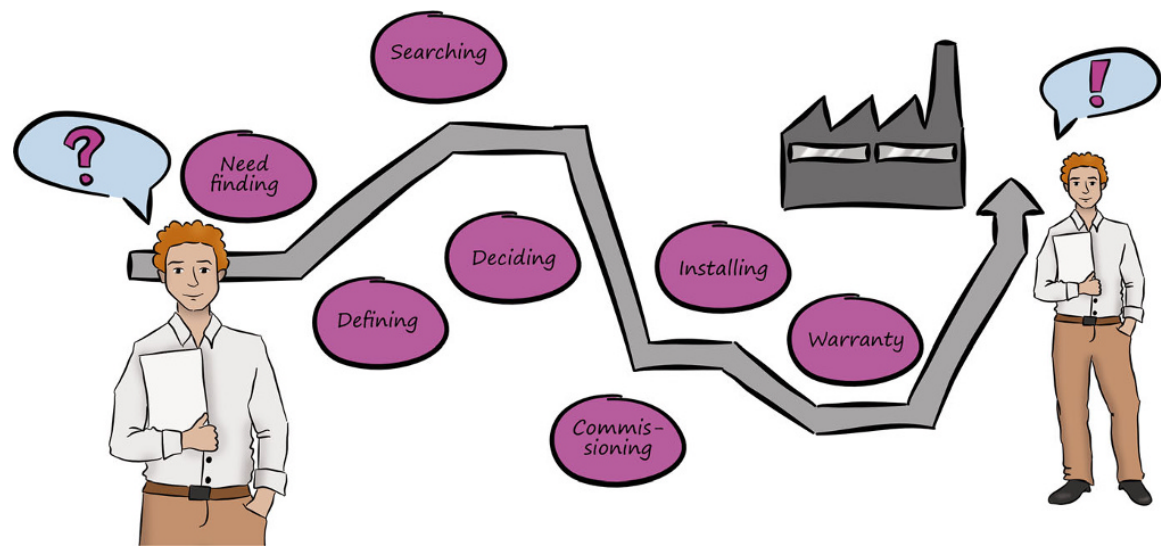

Fig. 3.28 An example of a visual journey (illustration by Annick Holland, adapted from West et al., 2020b)

Pen and paper work best, and keep the scope limited by looking at single interactions. You can use it internally as well as externally with your customers (Fig. 3.29).

\section{Other Tools}

In addition to the tools provided in this section, we suggest the book This is Service Design Doing (Stickdorn et al., 2018), which offers many examples of how firms have created or improved services in a highly practical way. The book is supported by a website (https://www.thisisservicedesigndoing.com). The Service Design Tools website (https://servicedesigntools.org) is also helpful with tools and tutorials. Again, Polaine et al. (2013) wrote an excellent book on service design entitled Service Design: From Insight to Implementation that provides more insights into the design and delivery of services. Even SAP scenes are an excellent tool kit, as they allow you to easily create storyboards and service prototypes. These are freely available on the Internet from SAP and need little introduction (https://community. sap.com/topics/fiori). Finally, IBM's enterprise design thinking website (https:// www.ibm.com/design/thinking/) provides more tools and a handy PDF that can help you with developing services in your business. 


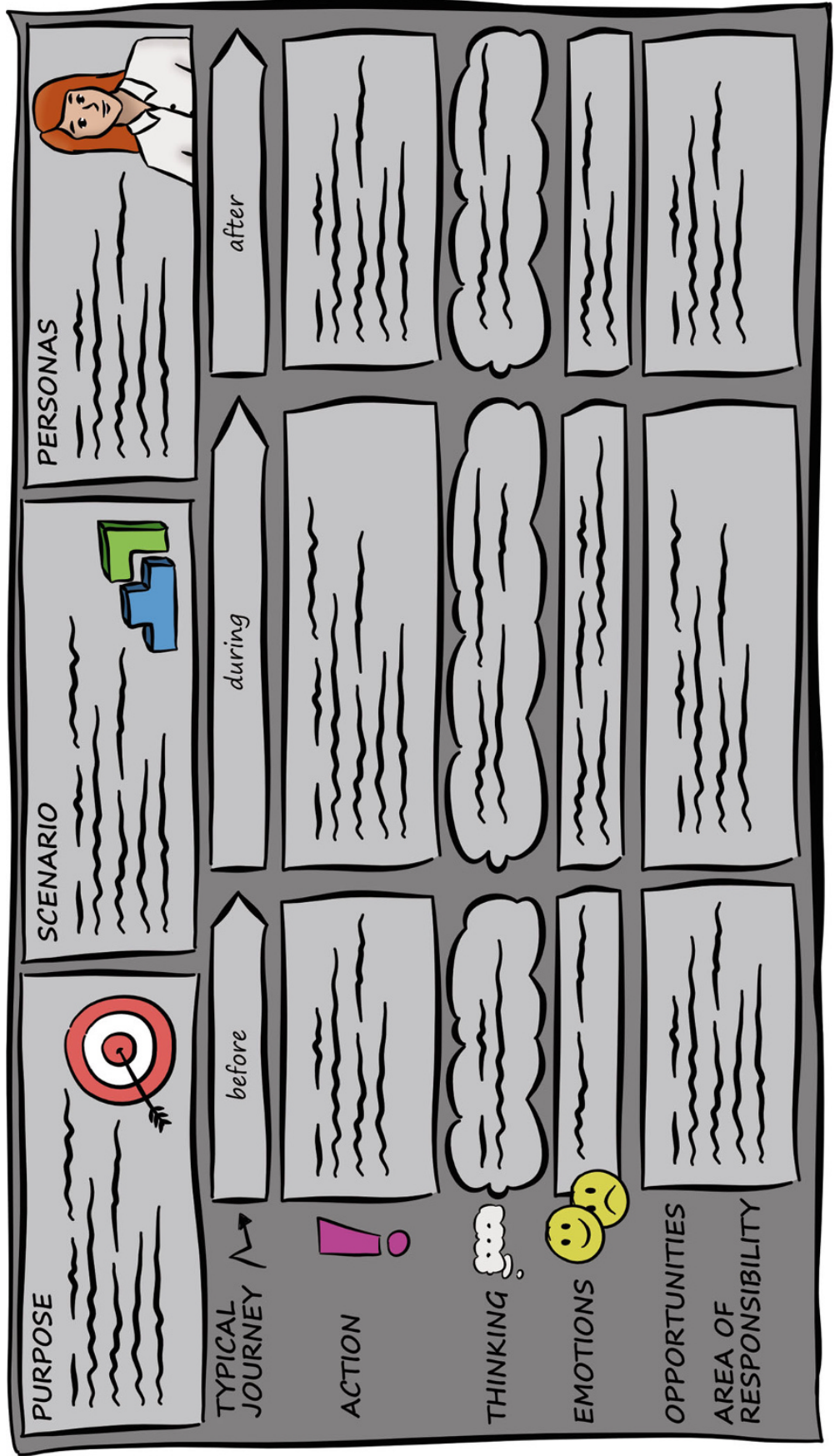

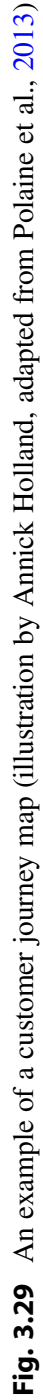




\section{References}

Carleton, T., Cockayne, W., \& Tahvanainen, A-J. (2013). Playbook for strategic foresight and innovation. Accessed December 30, 2020, from https://www.innovation.io/playbook

Christensen, C. M., Hall, T., Dillon, K., \& Duncan, D. S. (2016). Know your customers' "jobs to be done." Harvard Business Review.

Dmitrijeva, J., Schroeder, A., Ziaee Bigdeli, A., \& Baines, T. (2020). Context matters: how internal and external factors impact servitization. Production

Eckerson, W. (2009). Performance management strategies: How to create and deploy effective metrics. The Data Warehousing Institute. Accessed December 30, 2020, from ftp://public.dhe.

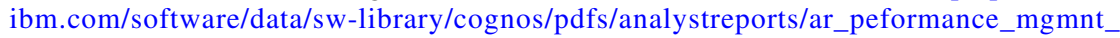
strategies_how_to_create_and_deploy_effective_metrics.pdf

Harniess, W., \& Harniess, W. (2020). Personas. In Red, white and radical. Routledge. https://doi. org/10.4324/9780429054198-3

IBM. (2018). Enterprise design thinking - Field guide. IBM Studios. Accessed December 29, 2020, from ibm.biz/fieldguide-public

Kumar, K., Zindani, D., \& Davim, J. P. (2020). Introduction to design thinking. In SpringerBriefs in Applied Sciences and Technology. https://doi.org/10.1007/978-3-030-31359-3_1

Lynn, S. G. (1984). Designing services that deliver. Harvard Business Review, 62(1), 133-139.

Meinel, C., \& Leifer, L. (2015). Introduction - Design thinking is mainly about building innovators. In H. Plattner, C. Meinel, \& L. Leifer (Eds.), Design thinking research. Understanding innovation. Springer. https://doi.org/10.1007/978-3-319-06823-7_1

Osterwalder, A., \& Pigneur, Y. (2010). Business model generation - Canvas. Wiley.

Pojasek, R. B. (2000). Asking “Why?" five times. Environmental Quality Management. https://doi. org/10.1002/1520-6483(200023)10:1<79::AID-TQEM10>3.0.CO;2-H

Polaine, A., Løvlie, L., \& Reason, B. (2013). Service design: From insight to implementation. Rosenfeld Media.

Stickdorn, M., Lawrence, A., Hormess, M., \& Schneider, J. (2018). This is service design doing. O'Reilly Media.

Stoll O., West S., Rapaccini M., Barbieri C., Bonfanti A., \& Gombac A. (2020). Upgrading the Data2Action framework: Results deriving from its application in the printing industry. In: Nóvoa H., Drăgoicea M., Kühl N. (eds) Exploring Service Science. IESS 2020. Lecture Notes in Business Information Processing, 377. Springer, Cham. https://doi.org/10.1007/978-3-03038724-2_20

Tseng, M. M., Qinhai, M., \& Su, C. (1999). Mapping customers' service experience for operations improvement. Business Process Management Journal, 5(1), 50-64. https://doi.org/10.1108/ 14637159910249126

Ulwick, A. W. (2002). Turn customer input into innovation. Harvard Business Review, 80(1), 91-98.

Ulwick, A. W. (2005). What customers want: Using outcome-driven innovation to create breakthrough products and services. McGraw-Hill.

West, S. S., \& Pascual, A. (2015). The use of equipment life-cycle analysis to identify new service opportunities. In T. Baines \& D. K. Harrison (Eds.), Servitization: The theory and impact: Proceedings of the Spring Servitization Conference 18-19 May 2015, SSC2015. Aston University.

West, S.S., Müller-Csernetzky, P., \& Huonder, M. (2018a). Ecosystems innovation for service development. Practices and Tools for Servitization. https://doi.org/10.1007/978-3-319-76517-4

West, S.S., Rohner, D., Kujawski, D, and Rapaccini, M. (2018b). Value-scope-price: Design and pricing of advanced service offerings based on customer value. Practices and Tools for Servitization. https://doi.org/10.1007/978-3-319-76517-4 
West, S. S., Stoll, O., \& Mueller-Csernetzky, P. (2020a). 'Avatar journey mapping' for manufacturing firms to reveal smart-service opportunities over the product life-cycle. International Journal of Business Environment. https://doi.org/10.1504/IJBE.2020.110906

West, S. S., Stoll, O., Østerlund, M., Müller-Csernetzky, P., Keiderling, F., \& Kowalkowski, C. (2020b). Adjusting customer journey mapping for application in industrial product-service systems. International Journal of Business Environment, 11(3), 275-297. https://doi.org/10. 1504/IJBE.2020.110911

Wikipedia. (2020). Five Ws. Wikipedia. Accessed December 30, 2020, from https://en.wikipedia. org/wiki/Five_Ws

Wikström, A., Everskog, A., Forsberg Wallin, A., Hyltefors, M., Larsen, S., \& Verganti, R. (2013). Storyboarding - Framing the "frame" of opportunity. In Proceedings of the International Conference on Engineering Design, ICED.

Open Access This chapter is licensed under the terms of the Creative Commons Attribution 4.0 International License (http://creativecommons.org/licenses/by/4.0/), which permits use, sharing, adaptation, distribution and reproduction in any medium or format, as long as you give appropriate credit to the original author(s) and the source, provide a link to the Creative Commons license and indicate if changes were made.

The images or other third party material in this chapter are included in the chapter's Creative Commons license, unless indicated otherwise in a credit line to the material. If material is not included in the chapter's Creative Commons license and your intended use is not permitted by statutory regulation or exceeds the permitted use, you will need to obtain permission directly from the copyright holder.

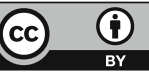

